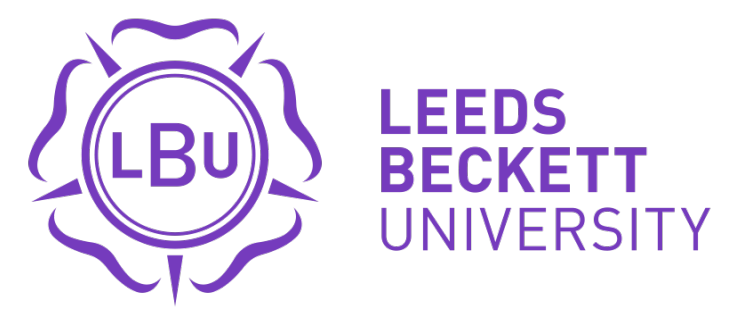

Citation:

Han, L-H and Zhou, K and Tan, Q-H and Song, T-Y (2020) Performance of steel reinforced concrete columns after exposure to fire: Numerical analysis and application. Engineering Structures, 211. p. 110421. ISSN 0141-0296 DOI: https://doi.org/10.1016/j.engstruct.2020.110421

Link to Leeds Beckett Repository record:

https://eprints.leedsbeckett.ac.uk/id/eprint/7012/

Document Version:

Article (Accepted Version)

Creative Commons: Attribution-Noncommercial-No Derivative Works 4.0

The aim of the Leeds Beckett Repository is to provide open access to our research, as required by funder policies and permitted by publishers and copyright law.

The Leeds Beckett repository holds a wide range of publications, each of which has been checked for copyright and the relevant embargo period has been applied by the Research Services team.

We operate on a standard take-down policy. If you are the author or publisher of an output and you would like it removed from the repository, please contact us and we will investigate on a case-by-case basis.

Each thesis in the repository has been cleared where necessary by the author for third party copyright. If you would like a thesis to be removed from the repository or believe there is an issue with copyright, please contact us on openaccess@leedsbeckett.ac.uk and we will investigate on a case-by-case basis. 
Research highlights:

- Performance of steel reinforced concrete columns after exposure to fire

- Parametric study of the influencing pararmters on post-fire residual strength

- Assessment method for fire-exposed steel reinforced concrete column and a case study 


\title{
Performance of steel reinforced concrete columns after exposure to fire: numerical analysis and application
}

\author{
**Lin-Hai Han ${ }^{1}$, Kan Zhou ${ }^{1}$, Qing-Hua Tan ${ }^{2}$ and Tian-Yi Song ${ }^{3}$ \\ ${ }^{1}$ Department of Civil Engineering, Tsinghua University, Beijing, 100084, China. \\ ${ }^{2}$ Department of Material Science and Engineering, National University of Defense Technology, \\ Hunan Province, 410072, China. \\ ${ }^{3}$ College of Architecture and Civil Engineering, Beijing University of Technology, Beijing 100124, \\ China.
}

\begin{abstract}
:
One advantage of steel reinforced concrete (SRC) columns is that the concrete encasement reduces the maximum temperature attained by the steel section in the full-range fire situation. For fire-exposed SRC columns, a better understanding of their post-fire performance can facilitate their rehabilitation and re-use. This paper presents a numerical study into the post-fire performance of SRC columns. Results show that an SRC column of $600 \times 600 \mathrm{~mm}$ in cross-section retained 0.87 times of the original load-bearing capacity after exposure to full-range fire with a heating duration of 45 min and a subsequent linear cooling down phase of 139 min. After the SRC column fully cooled down to ambient temperature, the proportion of load carried by the steel section increased to $73 \%$, significantly higher than the level at ambient temperature (20\%). Results of the parametric study revealed that a number of factors, i.e., duration of fire exposure, cross-sectional size, slenderness ratio and concrete strength, significantly affected the post-fire residual strength. The numerical method was applied to the post-fire assessment of the SRC columns in a fire-exposed building and a case study is presented. The resistance of the SRC column to compression reduced by $4 \%$ after fire exposure. By using the proposed repair method, the resistance to compression can be recovered by $11 \%$ compared to that before fire exposure.
\end{abstract}

\section{KEYWORDS:}

Steel reinforced concrete (SRC); concrete-encased steel section; composite column; post-fire; residual strength; assessment method.

**Correspondence address: Lin-Hai Han, Department of Civil Engineering, Tsinghua University, Beijing, 100084, China. Tel \& Fax: 8610 62797067, E-mail address: lhhan@tsinghua.edu.cn (L-H Han) 


\section{NOTATION}

$A_{\mathrm{c}} \quad$ Cross-sectional area of the concrete

$A_{s} \quad$ Cross-sectional area of the steel section

$A_{\mathrm{sb}} \quad$ Cross-sectional area of the longitudinal reinforcements

$B \quad$ Width of the composite cross-section

$b_{\mathrm{f}} \quad$ Width of the steel section

C Sectional perimeter

$D \quad$ Depth of the composite cross-section

$d \quad$ Diameter of the longitudinal reinforcement

$e \quad$ Eccentricity

$f_{\text {cu }} \quad$ Compressive cube strength of the concrete at ambient temperature

$f_{\mathrm{y}} \quad$ Yield strength of the steel at ambient temperature

$f_{\mathrm{yb}} \quad$ Yield strength of the longitudinal reinforcement at ambient temperature

$H \quad$ Height of the column

$h_{\mathrm{f}} \quad$ Height of the steel section

$K \quad$ Flexural stiffness

$k_{\mathrm{r}} \quad$ Reduction coefficient for the post-fire residual strength

$l \quad$ Effective length

$M \quad$ Bending moment

$M_{\mathrm{f}} \quad$ Bending moment in the fire situation

$M_{\mathrm{u}} \quad$ Resistance to bending at ambient temperature

$M_{\text {ur }} \quad$ Post-fire resistance to bending

$N \quad$ Compressive load or axial force

$N_{\mathrm{f}} \quad$ Compressive load in the fire situation

$N_{\mathrm{u}} \quad$ Resistance to axial compression at ambient temperature

$N_{\text {ur }} \quad$ Post-fire resistance to axial compression

$n \quad$ Load ratio, $n=N_{\mathrm{f}} / N_{\mathrm{u}}$

$t_{\mathrm{f}} \quad$ Thickness of the flange of the steel section

$t_{\mathrm{h}} \quad$ Duration of fire exposure/heating phase

$t_{\mathrm{w}} \quad$ Thickness of the web of the steel section

$t \quad$ Time

$\Delta_{\mathrm{c}} \quad$ Axial deformation

$\alpha \quad$ Sectional steel ratio, $\alpha=A_{\mathrm{s}} / A_{\mathrm{c}}$

$\beta \quad$ Aspect ratio

$\varepsilon \quad$ Strain

$\phi \quad$ Curvature

$\theta \quad$ Temperature, in ${ }^{\circ} \mathrm{C}$

$\theta_{\max }$ Maximum temperature attained during the heating and cooling phases, in ${ }^{\circ} \mathrm{C}$

$\lambda \quad$ Slenderness ratio

$\rho \quad$ Reinforcement ratio, $\rho=A_{\mathrm{sb}} / A_{\mathrm{c}}$

$\sigma \quad$ Stress 


\section{Introduction}

Steel reinforced concrete (SRC) columns, also known as concrete-encased steel composite columns, are composed of an inner steel section, longitudinal reinforcements, stirrups and outer concrete. Stemming from steel structures [1], SRC columns are nowadays widely used as load-bearing members in multi-storey buildings owing to the enhanced structural performance both at ambient temperature and in the fire situation. Through appropriate design, this type of columns can benefit from composite action and achieve enhanced stiffness and strength. Local buckling of the steel section can also be minimised. In terms of fire behaviour, SRC columns exhibit an exceptional fire resistance without additional fire protection due to the thermal insulation of the concrete. Codes for the fire design of SRC columns are available. The mechanical contribution of the outer concrete is either ignored (i.e., regarded an insulating material for the steel section) [2] or taken into consideration [3].

In 2009, a fire broke out in a 159-meter-high building where SRC columns were used as one type of the main vertical load-bearing members. The fire lasted for about $6 \mathrm{~h}$ (Fig.1a, Hou et al.[4]). Fig.1b shows a fire-exposed interior SRC column: its surface was blackened and the concrete cover spalled locally. After the fire, a preliminary inspection of the structures revealed that the fire did not cause a significant structural damage to vertical load bearing members and it was likely to reuse the main structure after appropriate repair. An issue emerging at the initial stages of the post-fire assessment was how to assess the structural damage of the fire-exposed SRC columns and how to conduct the structural repair. Establishing a fundamental understanding of the structural performance of fire-exposed SRC columns would serve as a preliminary step.

Researchers have conducted extensive experimental and numerical studies on the fire performance of SRC columns over recent decades. However, these studies mainly focused on the structural behaviour in the fire situation; limited study is available on the post-fire response. For example, the effects of axial restraint, cross-sectional dimensions and load level on the fire resistance has been examined [5]-[7]. The equations to predict the ultimate strength of SRC columns in the fire situation 
is available [8]. Concrete explosive spalling (CES) reduces the fire resistance of SRC columns [9]. The restraint of surrounding structures affects the fire resistance and the failure modes of SRC columns [10]-[12]. Ellobody [13] has condcted a detailed review of the relevant literature. Han et al. [14] summarized the studies on sub-assemblies, e.g., joints and frames, consisting of SRC columns. Additionally, studies on the fire performance of other types of steel-concrete composite columns [15]-[20] and joints comprising partially encased steel columns [21] are available. Furthermore, Espinos et al. [22] concluded that employing inner steel sections could improve the fire performance of conventional concrete-filled steel tubular (CFST) columns. These studies provide important insights into the fire performance of SRC columns.

The studies of the post-fire behaviour of SRC columns/composite structures are relatively limited. Zhang et al. [23] conducted an experimental investigation and identified that failure of SRC columns could occur during the cooling down phase. The studies dealing with the numerical modelling of structures exposed to natural fires and the post-fire residual capacity are available, but they mostly focus on CFST columns [24]-[32], concrete-filled double-skin tube columns [33] and concrete-encased CFST columns [34]-[35]. The practice of repairing fire-damaged steel/concrete structures is available [36]-[38], although no such practice could be found for SRC columns. These documents have developed an understanding of the behaviour of fire-exposed structural members.

To the best knowledge of the partners involved in the appraisal of the aforementioned building, no established knowledge was available for the post-fire performance of SRC columns, presumably because: 1) fire incidents occurred in buildings using SRC columns were rarely reported; and 2) the study of their post-fire performance was inhibited by the costly fire tests. Since SRC columns are usually designed to be the main vertical load-bearing members, they tend to have large cross-sectional dimensions. It is likely that they do not experience major structural damage due to the insulation of the concrete encasement, and hence the fire-induced damage is reparable. To fill this research gap and to facilitate the retrofit and rehabilitation of the fire-exposed building, the first author's research team experimentally and numerically conducted a series of studies into the post-fire performance of SRC columns. The authors have conducted preliminary experimental studies and 
have established finite element analysis (FEA) models to simulate the fire response of SRC columns [39]-[40]. Fig.2 shows a typical cross-section of an SRC column that was studied. This paper extends the numerical study of the post-fire performance of SRC columns and the main body contains three sections. Section 2 examines the post-fire performance of SRC columns, including resistance to combined compression and bending, failure modes and redistribution of internal forces. Section 3 presents a parametric study on the post-fire residual strength of SRC columns. Section 4 gives a post-fire assessment method for SRC columns and a case study demonstrating the use of this method.

\section{Post-fire performance of SRC columns}

This section presents a numerical investigation into the post-fire performance of SRC columns to establish a preliminary knowledge for assessing their residual strength. Detailed establishment and validation of the FEA models are available in refs. [39]-[40]. For simplicity, the FEA model is introduced briefly herein.

\subsection{Brief introduction of FEA models}

The sequentially coupled thermal analysis available in software package Abaqus [41] was used to establish the FEA model. The heat transfer analysis had one analysis step combining the heating and cooling phases, whilst the subsequent stress analysis comprised three steps. To evaluate the post-fire behaviour, the combined actions from axial compression and fire exposure were considered in the full-range fire scenario, which included four phases, i.e., an initial phase for applying load at ambient temperature (to simulate the pre-fire stage), a heating phase (standard fire exposure), a subsequent cooling down phase, and a post-fire phase. Detailed schematic graphs for these full-range fire phases and the determination of material properties are available in [40].

Fig. 3 illustrates the variations of stress-strain relationships of steel grade Q335 (yield strength $f_{\mathrm{y}}=335 \mathrm{MPa}$ ) and concrete class $\mathrm{C} 40 / 50$ (cube strength $f_{\mathrm{cu}}=50 \mathrm{MPa}$ ). Generally, the yield strength of steel was assumed to recover during cooling down (Fig. 3a). The stress-strain relationships of steel during cooling down were determined by an assumption that their expressions were identical with those at elevated temperature (and post-fire); but using the cooling peak strengths (and the 
corresponding strains) which were determined by linear interpolation taking the cooling temperature (i.e., the lower temperature during cooling after the attainment of maximum temperature, $\theta_{\max }$ ) as the independent variable. Unlike steel, the mechanical properties of concrete during cooling down continues deteriorating [3]; therefore, the properties of concrete at any temperature during cooling was assumed to be identical with those cooled down to ambient temperature (Fig. 3b). The reasons for these assumptions were a lack of test data and constitutive models for the cooling down phase, but the feasibility and accuracy of this assumption has been proved by previous studies [35][39]-[40][42].

Theoretically, the thermal properties for the cooling down phase are not identical with those for the heating phase. Due to the complexity of their determination and a lack of comprehensive experimental evidence, the thermal properties of concrete during cooling down and steel were therefore assumed to be reversible, ignoring the effects of residual thermal expansion. Previous study using the same assumption [42] generated acceptable predictions for the temperature development. Experimental evidence suggests that the thermal conductivity of concrete in the cooling phase is lower than that in the heating phase [43], which indicated the assumption of reversibility might generate lower temperature for the inner cross-section. However, considering the combined effect of other factors (e.g. variations in the specific heat of concrete and the thermal properties of steel), it is difficult to evaluate the qualitative changes if the true thermal properties in the cooling phase are included.

For the heating phase, the standard temperature-time curve was used. For the subsequent cooling down phase, the temperature was assumed to decrease linearly at a rate dependent on the duration of heating phase [44]. The main reason of using the standard fire curve rather than a realistic fire curve obtained from fire dynamics was because: (1) no validated constitutive models can consider both in-fire and post-fire material behaviour; and (2) most test data and corresponding validations are conducted in the standard fire. The effects of cooling method and cooling rate were not the aim of this paper, and hence were not studied explicitly. Note that the assumed linear cooling pattern could lead to nonconservative results because the inner cross-section might attained a higher maximum 
temperature when subjected to a slower cooling rate.

In the stress analysis, the first step (initial phase) was employed to apply load. The second step, importing the temperature obtained from the heat transfer analysis as predefined fields, was used for obtaining the structural response in the fire condition. The last step (post-fire phase) was used for analysing the post-fire structural response. The technique of 'restart' analysis was used in the third step to improve computational efficiency, as explained in Section 2.2. A user-defined subroutine ('USDFLD', in conjunction with 'UEXPAN') was used to introduce temperature-dependent material properties over the four phases. 'Tie' and 'Embedded' constraints were used to simulate the steel section-concrete interface and the reinforcement-concrete interface, respectively. A sensitivity analysis was conducted to determine the optimal element sizes. The final sizes in the direction of depth and width were 10-20 mm, whilst those along the height/longitudinal direction was two times greater, i.e., $20-40 \mathrm{~mm}$.

In the numerical study, the values of parameters (Table 1) were determined according to Eurocode EN 1994-1-1 [45], Chinese code JGJ 138-2001 [46] and existing construction practice, particularly the aforementioned fire-exposed building. The parameters are categorised into three types:

(1) Geometrical parameters: sectional perimeter, $C,(=2 B+2 D, B$ and $D$ are the width and the depth of the cross-section, respectively); aspect ratio of cross-section, $\beta,(=D / B)$; slenderness ratio, $\lambda$, $\left(=2 \sqrt{3} l / B, l\right.$ is the effective length); structural steel ratio, $\alpha,\left(=A_{\mathrm{s}} / A_{\mathrm{c}}, A_{\mathrm{s}}\right.$ and $A_{\mathrm{c}}$ are the cross-sectional areas of the steel section and the concrete, respectively); reinforcement ratio, $\rho$, ( $=A_{\mathrm{sb}} / A_{\mathrm{c}}, A_{\mathrm{sb}}$ is the cross-sectional area of the longitudinal reinforcements).

(2) Parameters related to actions: duration of fire exposure, $t_{\mathrm{h}}$; eccentricity ratio, $e / r$, $(e$ is the eccentricity of loading, $r=D / 2$ when about the major axis, $r=B / 2$ when about the minor axis); and load ratio, $n,\left(=N_{\mathrm{f}} / N_{\mathrm{u}}, N_{\mathrm{f}}\right.$ and $N_{\mathrm{u}}$ are the compressive load in the fire situation and the resistance to axial compression at ambient temperature, respectively).

(3) Physical parameters: yield strength of the steel section, $f_{y}$; yield strength of the longitudinal reinforcement, $f_{\mathrm{yb}}$; and compressive cube strength of the concrete, $f_{\mathrm{cu}}$. 
For the numerical simulations herein, failure of SRC columns under fire exposure was deemed to have occurred when: (1) axial contraction exceeded $H / 100 \mathrm{~mm}$, and (2) rate of axial contraction exceeded $3 H / 1000 \mathrm{~mm} / \mathrm{min}$, according to ISO 834-1 [47]. For the post-fire cases, failure was deemed to have occurred when either (1) the post-fire peak load was attained, or (2) axial contraction exceeded $H / 100 \mathrm{~mm}$.

To obtain the relationships between residual strength and fire exposure, duration of fire exposure/heating phase, $t_{\mathrm{h}}$, was taken as the main independent variable; for each combination of parameters, the post-fire residual strength was calculated assuming various $t_{\mathrm{h}}$-values, ranging from 0 to $90 \mathrm{~min}$ at intervals of $15 \mathrm{~min}$. The full length of the columns was assumed to be exposed to fire all around the column. Pinned-pinned boundary conditions were assumed. The concrete cover of reinforcements was $30 \mathrm{~mm}$ in thickness. The effect of fire-induced CES was ignored for $f_{\mathrm{cu}}=40$ and $60 \mathrm{MPa}$. For $f_{\text {cu }}=80 \mathrm{MPa}$, this effect was taken into account by the method proposed by Kodur et al [48]. This method assumes that CES occurs in the concrete cover of reinforcement when its temperature exceeds $350{ }^{\circ} \mathrm{C}$. Note that this one peak temperature-based approach does not reflect the actual behaviour of CES. The major limitation is that this method fails to consider the increase in spalling degree due to the increasing stress level of the unspalled concrete, and consequently might lead to nonconservative results because such inaccuracy could be a critical factor for the predictions of the behaviour of SRC column during/after fire exposure. The following values (underlined in Table 1) were used as a basic combination (Fig.2): $D \times B \times H=600 \times 600 \times 6000 \mathrm{~mm}$, $h_{\mathrm{f}} \times b_{\mathrm{f}} \times t_{\mathrm{w}} \times t_{\mathrm{f}}=360 \times 300 \times 16 \times 16 \mathrm{~mm}, f_{\mathrm{y}}=345 \mathrm{MPa}, f_{\mathrm{yb}}=335 \mathrm{MPa}, f_{\mathrm{cu}}=60 \mathrm{MPa}, \alpha=4 \%, \rho=1 \%, e / r=0$, $C=2400 \mathrm{~mm}, \lambda=35$ and $t_{\mathrm{h}}=45 \mathrm{~min}$. The full-range fire had a heating phase of $t_{\mathrm{h}}=45 \mathrm{~min}$ and a subsequent cooling phase of 139 min (the corresponding cooling rate was $9.38^{\circ} \mathrm{C} / \mathrm{min}$ ).

\subsection{Post-fire resistance to combined compression and bending}

For fire-exposed SRC columns with reparable damage, the information of residual strength is fundamental to the decision-making process and the method of repair. Establishing a preliminary understanding of the residual strength will facilitate the assessment procedure. 
The pre-fire and post-fire resistances of SRC columns to the combined compression and bending were obtained by the FEA models, as illustrated by the interaction curves in Fig.4. There are several reasons why the FEA models were adopted to obtain the post-fire $N-M$ interaction curves. Firstly, the FEA models allow the inclusion of the effects of initial loads on the post-fire response, as explained in the next paragraph. Secondly, it is beneficial and efficient to use the feature 'restart' in Abaqus to explore different post-fire loading paths (Fig.4). Thirdly, the internal forces of the SRC columns can be extracted and highlighted, as presented in Section 2.4.

For the ambient temperature situation, the resistance to axial compression, $N_{\mathrm{u}}$, and the resistance to pure bending, $M_{\mathrm{u}}$, were extracted respectively from the FEA models in a first step. In a second step, several parallel analyses were conducted: the resistances to the combination of axial compression and bending were determined by applying different levels of $N\left(<N_{\mathrm{u}}\right)$ and subsequently increasing the applied bending moment until the ultimate states were attained.

For the interaction curves of the fire-exposed SRC column, the method is described as follows. The column was subjected to an assumed load level ( $n=0.2$, point I in Fig.4) and a subsequent full-range fire with the load kept constant. Note that failure might occur during the heating phase, however, the duration of fire exposure was determined to be less than the fire resistance (obtained in a preliminary analysis) since this study focused on the post-fire residual strength. For a fire-exposed SRC column, its initial post-fire state was taken as the time when it fully cooled down to ambient temperature. Several parallel analyses were then performed using the 'restart' technique and all the subsequent analyses were appended to the same initial state. Among these parallel analyses, a first analysis was the case where the axial load was increased to obtain the post-fire resistance to pure axial compression, $N_{\text {ur }}$ (point $\mathrm{F}^{\prime}$ ). In a second analysis, the bending moment was increased to obtain the post-fire resistance to pure bending, $M_{\mathrm{ur}}$ (point $\mathrm{H}^{\prime}$ ). In a way similar to that of ambient temperature, the other analyses were conducted to obtain the intermediate ultimate states (curve $F^{\prime} G^{\prime} H^{\prime}$ ), i.e., the resistance to combined compression and bending: the axial load was increased to different levels and then the bending moment was increased until the ultimate states were attained. Arrows IJ and JK (Fig.4) showed this loading path. For comparison purpose, these ultimate states, i.e., the values of $N$ 
and $M$ have been normalised (divided by $N_{\mathrm{u}}$ and $M_{\mathrm{u}}$, respectively) such that the resistances at ambient temperature were equal to unity (points $\mathrm{F}$ and $\mathrm{H}$ in Fig.4).

The reduction of the resistance of SRC columns to compression and bending can be reflected by the inward shift of the interaction curve (from FGH to $\mathrm{F}^{\prime} \mathrm{G}^{\prime} \mathrm{H}^{\prime}$ ). As expected, the post-fire residual strength decreased by varying degrees dependent on load combination. For example, the resistance to pure compression decreased by $13 \%$ (from $\mathrm{F}$ to $\mathrm{F}^{\prime}$ ); whilst the resistance to pure bending dropped by 9\% (from $\mathrm{H}$ to $\mathrm{H}^{\prime}$ ). For this case, this loss of strength was mainly attributable to the fire-induced deterioration of material properties. The reduction of the resistance to combined compression and bending was graphically shown by the shaded area sandwiched between the two interaction curves (Fig.4). It indicated that the SRC column was likely to fail during full-range fire exposure (including the cooling phase) if the load combination imposed on it at ambient temperature lay in the sandwiched area. Note that curve $F^{\prime} G^{\prime} H^{\prime}$ was the resistance of the SRC column after fully cooling down to ambient temperature. Its resistance during fire exposure, however, could be even lower (indicated by the red-shaded area), which were not reflected by curve F'G'H'. That was mainly because it was assumed in the modelling that steel recovered its initial strength on cooling. Curve

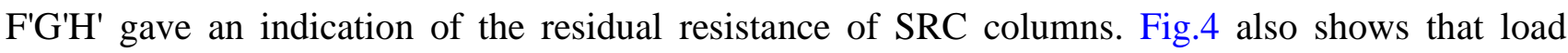
combination affected the post-fire residual resistance.

\subsection{Failure modes}

Two post-fire failure modes were identified for SRC columns, as shown in Fig.5, where the contour plots show the plastic strain of concrete in the longitudinal direction (PE33). The compression failure mode (corresponding to point $\mathrm{F}^{\prime}$ in Fig.4) was characterized by local crushing but no global buckling (Fig.5a). The failure mode was observed for the simulation cases where concentric axial load was applied and geometric imperfection showed a limited effect. In this case as shown in Fig.5a, two crushing zones formed near the upper and the lower ends where the plastic strain (negative denotes compressive strain in the contour) peaked. The concrete cover crushed, and the longitudinal reinforcements and the flange of the steel section buckled locally. This failure mode would be observed for actual stub columns. Additionally, it might also occur in the SRC columns whose 
cross-sectional area was significantly reduced by CES.

For slender columns, global buckling failure mode (corresponding to point H' in Fig.4) was observed, as shown in Fig.5b. A plastic hinge developed eventually at the mid-height due to the crushing of concrete at the concave side. The contours of plastics strain show that major tensile strains developed in the tension zone at the convex side. From the perspective of assessing the post-fire residual strength, the global buckling failure mode was less likely to occur because SRC columns were mostly design with a relatively low slenderness ratio to resist mainly axial compression.

The post-fire failure modes of SRC columns resembled those at ambient temperature. Note that the failure modes (Fig.5) were obtained from the cases without the effect of fire-induced CES. The randomness of fire-induced CES might result in a different/combined failure mode. Considering that one of the aims of this study is to serve the assessment and repair of fire-exposed building, it is more meaningful to incorporate the effect of CES with the aid of test evidence and fire scene investigation, as presented in Section 4.

\subsection{Redistribution of internal forces}

FEA modelling has the advantage of allowing the extraction of internal stress and section forces. To evaluate the contributions of different components to the post-fire load-bearing capacity, the internal forces were extracted from the mid-height cross-section by using the 'free body cut' function in Abaqus [41]. This function integrates the resultant forces and moments based on sectional outputs. Fig. 6 shows the axial load-time relationships for the cases shown in Fig. 5 ( $\left.t_{\mathrm{h}}=45 \mathrm{~min}\right)$. Note the time scales in the analysis steps of ambient phase and post-fire loading phase were the default time period, ranging from 0 to 1.0, in Abaqus. For clarity, these time scales have been magnified to make the differences observable; the ambient phase ranges from $0-5 \mathrm{~h}$ and post-fire loading phase starts from $45 \mathrm{~h}$ (Fig. 6). The heating and cooling phases, ranging from $5 \mathrm{~h}$ to $45 \mathrm{~h}$, are displayed in their natural time scale. The capital letter ' $\mathrm{C}$ ' in the legend in Fig. 6 denotes the forces obtained in the compression failure mode, whilst 'B' denotes the global buckling failure mode. The percentage rates show the proportion of the load carried by each component to the total axial force.

As expected, the fire exposure caused load redistributions in the early stage (5-10 h) of heating and 
cooling phases. The axial load carried by the steel section decreased between 5 and $6.3 \mathrm{~h}$ because the outer concrete was heated. The steel section even developed tension (-2\% of total axial force) at 6.3 h. Afterwards, the load carried by the steel section increased mainly because of the deterioration of outer concrete. At the end of the cooling phase it carried $73 \%$ of the total axial load, exceeding its contribution at the ambient phase (20\%). This $73 \%$ contribution was offset by the tension developed in the longitudinal reinforcements $(-46 \%)$. This confirmed that the steel section contributed significantly to the load bearing resistance in the post-fire situation.

For compression failure mode, in the process of post-fire loading the redistribution of the internal forces that occurred during the heating and cooling phases were counteracted. This was reflected by the proportions of load carried by different components when the SRC column attained its load-carrying capacity (49 h). The concrete, the longitudinal reinforcements and the steel section carried $64 \%, 7 \%$ and $28 \%$ of the total load, which showed an insignificant difference as compared with those at ambient temperature (76\%, 5\% and 20\%). This indicated that the fire-exposed SRC column could retain the composite action during the post-fire loading phase. For global buckling failure modes (suffixed with B), the steel section developed a tension force, making up -35\% of the total axial load. This demonstrated that the steel section significantly contributed to the post-fire resistance to bending.

\section{Effects of parameters on post-fire residual strength}

\subsection{Definition of strength reduction coefficient}

To serve the purpose of assessing the residual strength of a fire-exposed SRC column, a reduction coefficient $\left(k_{\mathrm{r}}\right)$ was used to quantify the extent of fire-induced damage. The definition of $k_{\mathrm{r}}$ is expressed in Eq. (1):

$$
k_{\mathrm{r}}=\frac{N_{\mathrm{ur}}\left(t_{\mathrm{h}}\right)}{N_{\mathrm{u}}}
$$

where $N_{\mathrm{u}}$ is the resistance to axial compression (buckling resistance) at ambient temperature, $N_{\mathrm{ur}}\left(t_{\mathrm{h}}\right)$ is the post-fire resistance to axial compression (buckling resistance), $t_{\mathrm{h}}$ is the duration of fire exposure. The following subsection presents the effects of various parameters (Table 1) on the 
reduction coefficient.

\subsection{Effects of parameters on reduction coefficient}

For each parameter, the $k_{\mathrm{r}}$-value is graphed against the main independent variable $t_{\mathrm{h}}$ (Fig.7). The parameters of $C, \lambda$ and $f_{\text {cu }}$ had a significant effect on $k_{\mathrm{r}}$ (Figs.7a, c and f). The $k_{\mathrm{r}}$-value increased with an increasing $C$, particularly when $C$ increased from $1600 \mathrm{~mm}$ to $2400 \mathrm{~mm}$ (Fig.7a). This trend was similar with CFST columns [25]. That is because a larger cross-section has greater thermal inertia; thus reducing the maximum temperature attained by the inner components, particularly the steel section. Interestingly, the above increasing trend became lesser when $C$ exceeded $2400 \mathrm{~mm}$ (i.e., the width of square section exceeded $600 \mathrm{~mm}$ ). That is because as $C$ increased, the maximum temperature of the inner components (particularly the steel section) tended to converge due to the thermal properties of the concrete. If this maximum temperature was lower than $400^{\circ} \mathrm{C}$ [3][49], steel recovered its initial strength on cooling down, and thus making no additional contribution to the decrease of the $k_{\mathrm{r}}$-value.

Fig.7c shows that $k_{\mathrm{r}}$ decreased with increasing $\lambda$, which was consistent with the buckling theory and previous research on CFST columns [25]. The buckling theory for columns might also apply for the determination of post-fire resistance of SRC columns; but using residual mechanical properties [32]. Furthermore, a greater $\lambda$ might generate more post-fire residual deformation, which added to the second-order effect for the post-fire loading. For all the cases, the lowest $k_{\mathrm{r}}$-value was 0.45 when $\lambda=70$ and $t_{\mathrm{h}}=90 \mathrm{~min}($ Fig. $7 \mathrm{c})$.

The $k_{\mathrm{r}}$-value decreased as $f_{\text {cu }}$ increased (Fig.7f). Particularly, the $k_{\mathrm{r}}$-value reduced by a greater extent when $f_{\text {cu }}$ increased from $60 \mathrm{MPa}$ to $80 \mathrm{MPa}$ as compared with that from $40 \mathrm{MPa}$ to $60 \mathrm{MPa}$. For example, the decreases of $k_{\mathrm{r}}$-values when $t_{\mathrm{h}}=90 \mathrm{~min}$ were $13 \%$ and $5 \%$ respectively. Two reasons might account for this. First, the load share at the attainment of plastics resistance was dependent on the material strengths. With load ratio kept constant, concrete of a greater strength class carried a higher proportion of external load (i.e., under higher stress level in the fire situation). Consequently, this caused greater damage to the concrete. Second, fire-induced CES was taken into account for 
$f_{\text {cu }}=80 \mathrm{MPa}$ in the modelling, which added to the reduction of $k_{\mathrm{r}}$. Earlier study on CFST columns [25] found that $f_{\text {cu }}$ has a minor effect on $k_{\mathrm{r}}$. The reason why the effect of $f_{\text {cu }}$ became remarkable for SRC columns might be that the concrete was on the outermost of the cross-section and exposed to fire directly.

The parameters of $n, f_{\mathrm{y}}$ and $\alpha$ had moderate effects on $k_{\mathrm{r}}$. As expected, the $k_{\mathrm{r}}$-value showed a decreasing trend with the increase of $n$ (Fig.7d), mainly because a greater stress level reduced the load-bearing capacity at elevated temperature by a greater extent. The $k_{\mathrm{r}}$-value (corresponding to $t_{\mathrm{h}}=90 \mathrm{~min}$ ) decreased by $5 \%$ when $n$ increased from 0.2 to 0.6 ; whereas for CFST columns the $k_{\mathrm{r}}$-value (corresponding to a heating time ratio, $t_{\mathrm{o}}=0.6$ ) increased from 0.35 to 0.75 [25]. These different trends resulted from the difference in the time scales. The previous study employed the heating time ratio, $t_{\mathrm{o}}$, defined by the ratio of heating time to the fire resistance, as the independent variable. The fire exposure time was determined by multiplying $t_{\mathrm{o}}$ with the fire resistance, which was preliminarily obtained in an analysis of the same member under the same load level. It is a well-known fact that a greater load level results in a lower fire resistance. Therefore, with $t_{\mathrm{o}}$ kept constant, when the load level increased the resultant $t_{\mathrm{h}}$-value used in the post-fire analysis of the CFST column became lower. By contrast, this study employed the duration in real time as the independent variable.

As expected, the two parameters related to the steel section, i.e., $f_{\mathrm{y}}$ and $\alpha$, showed similar trends. The $k_{\mathrm{r}}$-value increased with the increase of $f_{\mathrm{y}}$ (Fig.7g) or $\alpha$ (Fig.7i), mainly because increasing either $f_{\mathrm{y}}$ or $\alpha$ increases the contribution of the steel section to the total plastic resistance. Furthermore, increasing the strengths of the steel components, i.e., $f_{\mathrm{y}}$ and $f_{\mathrm{yb}}$ (Fig. $7 \mathrm{~g}$ and $\mathrm{h}$ ) seemed to be more beneficial in terms of retaining residual strength than that of the strength of the concrete $f_{\text {cu }}$ (Fig.7f). That is because the recovery of steel strength on cooling down was included in the modelling.

Other parameters, such as $\beta, e / r, f_{\mathrm{yb}}$, and $\rho$, had minor effects on $k_{\mathrm{r}}$. The $k_{\mathrm{r}}$-value decreased slightly with the increase of $\beta$ (Fig.7b), possibly because the columns with a higher $\beta$-value tended to fail about the minor axis. The effect of $f_{\mathrm{yb}}$ (Fig.7h) resembled that of $f_{\mathrm{y}}$. Compared with the effect of $\alpha$, 
the effect of $\rho$ (Fig.7j) was relatively minor, probably because the value of $\rho$ was relatively lower than $\alpha$ in this study. The effect of $e / r$ on $k_{\mathrm{r}}$ seemed to be complex; $e / r$ had a moderate effect on $k_{\mathrm{r}}$ when the fire exposure was shorter (e.g., $t_{\mathrm{h}}=15 \mathrm{~min}$ ), whereas a minor effect when $t_{\mathrm{h}}$ was greater (e.g., $t_{\mathrm{h}}=90 \mathrm{~min}$, Fig.7e). Fig.4 may help to understand this complexity. The residual resistance to axial compression varies depending on both the loading paths, e.g., $(e / r)_{1}$ and $(e / r)_{2}$, and the shape of the post-fire interaction curves.

\subsection{Effect of fire exposure on the residual strength}

Fig.7 also shows that $k_{\mathrm{r}}$ decreased with the increase of the duration of fire exposure, $t_{\mathrm{h}}$. The evolution in $t_{\mathrm{h}}$ of the residual strength of SRC columns is graphed schematically (Fig.8). As is well-known, the strength decreases with the increase of fire exposure time (curve CF). The rate of decrease can be gradual (segment CJ) for SRC columns when $t_{\mathrm{h}} \leq 90$ min due to the insulating effect of the concrete encasement, as shown in the subfigures in Fig.7. The limit state in the fire situation may be attained (indicated by point F) with ongoing fire exposure, and thus the slope of curve CF becomes steep (curve IF). This reflects the runaway failure of tested specimens. For an SRC column carrying the service load (e.g., point A), a fire exposure (arrow AG) and a subsequent cooling phase (GH) reduces its load-bearing capacity (by CB). As shown, Fig.8 incorporates the possible detrimental effect of the cooling down phase. For the purpose of post-fire assessment and repair, the state of post-fire load combination (point $\mathrm{H}$ ) and the residual strength (DJ) shall be identified. An appropriate repair method shall recover the load-bearing capacity to ensure structural safety.

\subsection{Simplified computation diagram of reduction coefficient}

Fig.9 gives a simplified computation diagram for estimating the reduction coefficient $\left(k_{\mathrm{r}}\right)$ for SRC columns. The parameters showing minor and moderate effects were omitted, therefore, the $k_{\mathrm{r}}$-value was dependent on the duration of fire exposure $\left(t_{\mathrm{h}}\right)$, the sectional perimeter $(C)$, the slenderness ratio ( $\lambda$ ) and the cube strength of concrete $\left(f_{\mathrm{cu}}\right)$. The ranges of validity for Fig.9 are $C=1600-4000 \mathrm{~mm}$, $\lambda=17.5-70.0, t_{\mathrm{h}}=0-90 \mathrm{~min}, f_{\mathrm{cu}}=40-80 \mathrm{MPa}, f_{\mathrm{y}}=235-420 \mathrm{MPa}, f_{\mathrm{yb}}=235-400 \mathrm{MPa}, \alpha=4 \%-8 \%, \rho=1 \%-3 \%$, and $e / r=0-0.9$. There are a number of limitations of this diagram. Note that the effect of fire-induced 
CES was incorporated for $f_{\mathrm{cu}}=80 \mathrm{MPa}$ only, and was evaluated based on the assumption that the concrete cover of reinforcement fully spalls when the concrete temperature reaches $350{ }^{\circ} \mathrm{C}$. The randomness of CES was ignored. Fig.9 applies to the standard fire exposure all around the columns and does not taken into account of the difference in temperature along the height. Therefore, this diagram gives an idea of how much the strength of the fire-exposed SRC columns might decrease, rather than a validated prediction. For assessing a real fire-exposed SRC column numerically, the detailed information of CES shall be incorporated. Furthermore, this diagram gives no data for some intermediate values, e.g. $f_{\mathrm{cu}}=70 \mathrm{MPa}$, due to the limited values taken in the parametric study.

\section{Application of post-fire assessment methodology}

The final section first describes the method adopted for assessing the fire-exposed SRC columns in the aforementioned building and then demonstrates the application of this method through a case study.

\subsection{Post-fire assessment guidelines}

As aforementioned, detailed guidelines for post-fire assessment and a few case studies for steel and concrete structures are available elsewhere [36]-[37]. For a fire-exposed steel-concrete composite structure, these guidelines can be referred to. The Chinese code CECS 252 [50] also provides a general procedure for post-fire investigation and structural assessment. The method for assessing the aforementioned fire-exposed SRC columns is shown in Fig.10. The flow chart involves five steps:

(1) Identification of reparable members with the aid of fire scene investigation report, building design documentation and structural inspection report;

(2) Determination of the performance of these members at ambient temperature by using advanced numerical models;

(3) Determination of post-fire residual structural characteristics;

(4) Design for repair; and

(5) Assessment of the proposed repair method and redesign if necessary.

The following subsection demonstrates the assessment and the repair of a specific SRC column 
(Fig.1b).

\subsection{Case study}

The fire-exposed complex comprised of a main high-rise structure and lower space grip structures. The former featured a tower (occupied rooftop being $137.9 \mathrm{~m}$ ), a basement and a podium (occupied rooftop being 11.9-23.9 m). The tower adopted shear wall-frame structural system, in which SRC columns were used as vertical load-bearing members. Detailed assessment process for the specific column is as follows.

\section{Step 1: Identification of reparable columns}

The fire investigation report categorised the fire-induced damage into four levels for structural members (Table 2). No structural repair was necessary for level 1 (superficial damage). For levels 2 (minor damage) and 3 (moderate damage), the fire-induced damage was regarded as reparable damage. The members belonging to level 4 (extensive damage) were unrepairable and should be scrapped. The information of the reparable column members was extracted from the report and compiled a list. This list revealed that the fire caused severe damage to the columns at floors 10 and 26D. For floor 10, thirty-nine structural members were identified as moderate damage (level 3) and the maximum depth of CES was $75 \mathrm{~mm}$. For floor 26D, ten structural members were classified into level 3 and the maximum depth of CES was $35 \mathrm{~mm}$.

In the remainder of this subsection, an SRC column (of damage level 3) at floor 10 is taken as an example (Fig.11). CES occurred on the north face of this column, partially exposing the reinforcement. The sizes of the CES were approximately $1200 \times 550 \mathrm{~mm}$, and the average depth was $25 \mathrm{~mm}$. The original cross-sectional dimensions of the column were $1250 \times 850 \mathrm{~mm}$. The dimensions of the encased steel section were $h_{\mathrm{f}}=600 \mathrm{~mm}, b_{\mathrm{f}}=300 \mathrm{~mm}, t_{\mathrm{f}}=t_{\mathrm{w}}=40 \mathrm{~mm}$. Thirty-six reinforcing bars of $28 \mathrm{~mm}$ in diameter were used. Stirrups of $16 \mathrm{~mm}$ in diameter were arranged at $100 \mathrm{~mm}$ intervals. The strengths of materials were $f_{\mathrm{cu}}=60 \mathrm{MPa}, f_{\mathrm{y}}=345 \mathrm{MPa}$ and $f_{\mathrm{yb}}=335 \mathrm{MPa}$. The design values of most unfavourable load combination were determined according to the design documents: $N=1.30 \times 10^{4} \mathrm{kN}, M_{\mathrm{x}}=220 \mathrm{kN} \cdot \mathrm{m}$ and $M_{\mathrm{y}}=214 \mathrm{kN} \cdot \mathrm{m}$. 


\section{Step 2: Determination of the performance at ambient temperature}

For comparison purpose, the structural performance of this column at ambient temperature was first obtained by the FEA model. The ultimate strength and the flexural stiffness were obtained to establish a fundamental understanding of the pre-fire structural performance. The data gathered in Step 1, e.g., preliminary data, including geometrical data and physical parameters and loads, were used as inputs to the FEA models. The height was determined assuming pin-ended conditions and the effective length factors provided by the design documentation. The effective length factors for bending about the major axis $\mathrm{x}$ and the minor axis $\mathrm{y}$ were both taken as 1.25. An additional eccentricity of the greater of $20 \mathrm{~mm}$ and $1 / 30$ of the sectional dimension was used in the FEA model as the initial imperfection according to Chinese code JGJ 138-2001 [46]. The predicted results are presented and discussed in Step 5.

\section{Step 3: Determination of the post-fire residual structural characteristic}

In this step, the post-fire residual strength and the stiffness of fire-exposed SRC columns were determined by the FEA model.

For the temperature history, the BFD fire curve proposed by Barnett [51] was adopted due to its simplicity: the temperature development is expressed by one equation with three factors. The curve reflects the temperature evolution of an indoor fire, including growth phase, flashover, fully developed phase and decay phase. Parameters, e.g., the effects of opening factor, the fire load mass density and the heating rate, were determined according to the investigation report. A two-zone model was used to differentiate the upper zone (higher temperature) from the lower zone (lower temperature). Their respective temperature versus time curves are shown in Fig.12.

The stress analysis was performed by using the FEA model, as described in Section 2.1. Fig.13 illustrates the boundary conditions and the meshing of the FEA model for this specific column. The actual severity (depth of spalling zone) and the region of CES were incorporated in the modelling. The time of occurrence of CES was determined according to the preliminary experimental study. The CES occurred at the concrete cover after $15 \mathrm{~min}$ of fire exposure and lasted for $20 \mathrm{~min}$ [40]. For simplicity, it was assumed that the CES occurred at $25 \mathrm{~min}$ of fire exposure. Furthermore, the 
interface between the high-strength compensating concrete and the original concrete was modelled by 'Tie' constraint, assuming a full-bond behaviour. The results are given in Fig. 14 and discussed in

\section{Step 5.}

Besides the above numerical method, an alternative method is to use the simplified computation diagram (Fig.9). The $t_{\mathrm{h}}$-value, $C$-value, $\lambda$-value and $f_{\text {cu}}$-value of a specific fire-exposed SRC column can be determined first according to the fire investigation report and the design documentation, and then the $k_{\mathrm{r}}$-value can be determined. Note that the $t_{\mathrm{h}}$-value shall be determined using the equivalent fire exposure time. For the specific SRC column (Fig.1b), $C=4200 \mathrm{~mm}, \lambda=20$ for about $y-y$ axis (and $\lambda=14$ for about $x$ - $x$ axis, Fig. 11$), f_{\text {cu }}=60 \mathrm{MPa}$, the equivalent fire exposure time $t_{\mathrm{h}}=23 \mathrm{~min}$ if the same maximum temperature $\left(800{ }^{\circ} \mathrm{C}\right.$ from the upper zone curve) is used to find the equivalent maximum temperature for standard fire curve. Therefore, the curve labelled ' $C=4000 \mathrm{~mm}, f_{\mathrm{cu}}=60 \mathrm{MPa}, \lambda=17.5$ ' in Fig. 9 might be used for an estimation, and it gives a $k_{\mathrm{r}}$-value of 0.83 .

\section{Step 4: Design for repair}

The design for repair was similar to the design for ambient temperature. According to the design drawings for repair, the design institute selected the method of sprayed concrete. For the specific column (Fig.11a), the repair method is detailed in Fig.11c. The proposed plan is introduced as follows: the burn marks and the crumbly surface were chipped off to expose the inner solid concrete; the exposed area exceeded that of the original concrete by at least $100 \mathrm{~mm}$ in radius direction to ensure bond performance. Any rust on exposed reinforcement was removed. The surface was then cleaned with wire brush and pressure washer sequentially. The moisture content of the surface was monitored to ensure it satisfied the application of glue and concrete. After the glue was applied on the surface, new reinforcement was placed and fastened with rivets. High-strength compensating concrete/sprayed concrete was projected onto the surface, followed by standard procedure of curing. The strength of the compensating concrete was $5 \mathrm{MPa}$ higher than the strength of the original concrete. The dimensions of the repaired cross-section exceeded the original by $120 \mathrm{~mm}(60 \mathrm{~mm}$ at each end). 


\section{Step 5: Assessment of the repair effect}

To assess the repair effect, the FEA model was used to evaluate the proposed repair design. For comparison, the strength and the axial stiffness of the SRC column before fire exposure, after fire exposure and after repair were extracted from different analyses. From a technical perspective, the design for repair shall principally ensure that the performance of repaired column exceeds the pre-fire level. Otherwise, redesign shall be conducted, followed by successive structural analysis. Note that the structural performance was the only focus herein; whereas for the real project, various factors were taken into consideration, e.g. cost and construction time.

For the analysis of the repaired column, the fire-induced deterioration of the original materials (including concrete, steel and reinforcement) was incorporated and imported by using the capability of 'transferring results from one Abaqus/Standard analysis to another' in Abaqus. The final material states from the structural analysis in Step 3 were imported into this analysis model as initial states, such that the original materials inherited these states in the subsequent analysis. For the new repairing materials, no initial state was applied.

Fig.14 shows the interaction curves of the SRC columns at different stages. For this specific column, the resistance to compression after exposure to fire reduced by $4 \%$, whereas the resistances to bending moment about both axes decreased by $4 \%$. By comparison, $k_{\mathrm{r}}$ was estimated to be 0.83 according to Fig.9 (Step 3). This conservative result is within expectation because the temperature of the upper zone (Fig.12) was used to determine the maximum temperature (thus the equivalent fire exposure time) for the full length of the column.

The interaction curves for the repaired column shifted outside, covering a larger area than that before fire (Fig.14). The resistance to axial compression increased by $11 \%$ as compared with the post-fire resistance. The increase of the resistance to bending about the minor axis seemed to exceed that of the major axis. This is probably because the encasing material was also applied to the region where CES occurred, besides the uniform depth of concrete (Fig.11c). These comparisons demonstrated that the repair method was capable of recovering the initial capacity.

The bending moment $(M)$ versus curvature $(\phi)$ relationships were also extracted to check the flexural 
stiffness (Fig.15). These curves were obtained by increasing the bending moment applied on the member in the FEA model. Fig. 15 shows that the fire exposure reduced the initial flexural stiffness in the late stage of bending, especially when $\phi$ exceeded $0.005 \mathrm{~m}^{-1}$. The proposed repair method was able to recover the flexural stiffness to the pre-fire level. The flexural stiffness, $K$, is defined by the secant flexural stiffness corresponding to 0.6 times of the maximum bending resistance in the $M-\phi$ curves, and listed in Fig.15. It shows that $K$ decreased by $14 \%$ and $18 \%$ after exposure to fire for bending about axes $x$ and $y$ respectively. By using the proposed repair method, $K$-value recovered by $7 \%$ and $8 \%$ compared to the post-fire levels. This again confirmed that the repair method was able to recover the flexural stiffness. Additionally, Fig.15 also shows that the flexural stiffness for bending about the minor axis also tended to recover by a greater extent.

The above case study shows that the repair method was able to recover the strength and the flexural stiffness of the specific SRC column. Note that these were based on several assumptions, e.g., a perfect bond behaviour between the new and the original materials. The study presented above served the post-fire assessment and the actual design for repair of the fire-exposed SRC columns.

\section{Conclusions}

Within the limitations of the work conducted in this paper, the following conclusions can be drawn:

(1) The post-fire resistance of SRC columns to the combined compression and bending was reduced to varying degrees dependent on a variety of parameters. An SRC column of $600 \times 600 \mathrm{~mm}$ in cross-section retained 0.87 times of the initial resistance to axial compression and 0.91 times of the initial resistance to pure bending after a full-range fire exposure of $45 \mathrm{~min}$ and a subsequent cooling down phase of $139 \mathrm{~min}$. The development of the internal forces of the SRC column showed that the steel section carried $73 \%$ of the total axial load after cooling down, whilst its contribution was $20 \%$ at ambient temperature.

(2) The duration of fire exposure, as well as the sectional perimeter, the slenderness ratio and the concrete cube strength, were identified to have a significant effect on the post-fire reduction coefficient. For a stocky $(\lambda<=17.5)$ SRC column of $600 \times 600 \mathrm{~mm}$ in cross-section (concrete 
strength=60 MPa) after exposure to full-range fire with heating phase of $45 \mathrm{~min}$ and $90 \mathrm{~min}$, the reduction coefficients were 0.87 and 0.75 , respectively. Unlike CFST columns, the reduction coefficient of SRC columns was affected significantly by the concrete strength.

(3) The case study shows that the resistance of the specific SRC column to compression reduced by $4 \%$ after fire, whereas by adopting the proposed repair method, the resistance of the repaired SRC column could be increased by $11 \%$ compared with that the post-fire resistance. The flexural stiffness decreased by $14 \%$ after fire, and improved by $7 \%$ compared with the pre-fire level. The assessment confirmed that the repair method was able to recover the load-bearing capacity and the flexural stiffness effectively.

\section{Acknowledgements}

This research is part of the project supported by the National Key R\&D Program of China (No. 2018YFC0807600). The financial support is highly appreciated.

\section{References}

[1] Malhotra HL, Stevens RF, BRS, 449 B. Fire resistance of encased steel stanchions. Proceedings of the Institution of Civil Engineers. 1964;27:77-98.

[2] ASCE/SEI/SFPE 29-05. Standard calculation methods for structural fire protection. American Society of Civil Engineers; 2006.

[3] British Standard Institution (BSI). BS EN 1994-1-2:2005+A1:2014. Eurocode 4 - Design of composite steel and concrete structures; Part 1-2: General rules-Structural fire design. London, $\mathrm{UK} ; 2014$.

[4] Hou LF, Ming LI, Cui WY, Liu YC. Numerical Simulation and Analysis of On-building High-rise Building Fires. Procedia Engineering. 2011;11:127-34.

[5] Wang ZH, Tan KH. Residual area method for heat transfer analysis of concrete-encased I-sections in fire. Engineering Structures. 2006;28:411-22.

[6] Huang ZF, Tan KH, Toh WS, Phng GH. Fire resistance of composite columns with embedded I-section steel - Effects of section size and load level. Journal of Constructional Steel Research. $2008 ; 64: 312-25$. 
[7] Huang ZF, Tan KH, Phng GH. Axial restraint effects on the fire resistance of composite columns encasing I-section steel. Journal of Constructional Steel Research. 2007;63:437-47.

[8] Yu JT, Lu ZD, Xie Q. Nonlinear analysis of SRC columns subjected to fire. Fire Safety Journal. 2007;42:1-10.

[9] Mao X, Kodur VKR. Fire resistance of concrete encased steel columns under 3- and 4-side standard heating. Journal of Constructional Steel Research. 2011;67:270-80.

[10] Moura Correia AJP, Rodrigues JPC. Fire resistance of partially encased steel columns with restrained thermal elongation. Journal of Constructional Steel Research. 2011;67:593-601.

[11] Young B, Ellobody E. Performance of axially restrained concrete encased steel composite columns at elevated temperatures. Engineering Structures. 2011;33:245-54.

[12]Rodrigues JPC, Correia AJM, Pires TAC. Behaviour of composite columns made of totally encased steel sections in fire. Journal of Constructional Steel Research. 2015;105:97-106.

[13]Ellobody E. A consistent nonlinear approach for analysing steel, cold-formed steel, stainless steel and composite columns at ambient and fire conditions. Thin-Walled Structures. 2013;68:1-17.

[14]Han LH, Tan QH, Song TY. Fire Performance of Steel Reinforced Concrete (SRC) Structures. Procedia Engineering. 2013;62:46-55.

[15]Hong S, Varma AH. Analytical modeling of the standard fire behavior of loaded CFT columns, Journal of Constructional Steel Research 2009;65(1) 54-69.

[16] Schaumann P, Kodur V, Bahr O. Fire behaviour of hollow structural section steel columns filled with high strength concrete, Journal of Constructional Steel Research 2009; 65(8):1794-1802.

[17]Espinos A, Romero ML, Hospitaler A. Advanced model for predicting the fire response of concrete filled tubular columns, Journal of Constructional Steel Research 2010; 66(8):1030-1046.

[18]Espinos A, Gardner L, Romero ML, Hospitaler A. Fire behaviour of concrete filled elliptical steel columns, Thin-Walled Structures. 2011; 49(2): 239-255.

[19]Neuenschwander M, Knobloch M, Fontana M. ISO Standard Fire Tests of Concrete-Filled Steel 
Tube Columns with Solid Steel Core, Journal of Structural Engineering. 2017; 143(4):04016211.

[20]Neuenschwander M, Knobloch M, Fontana M. Modeling thermo-mechanical behavior of concrete-filled steel tube columns with solid steel core subjected to fire, Engineering Structures. 2017;136:180-193.

[21]Huang S-S, Davison B, Burgess IW. High-temperature tests on joints to steel and partially-encased $+\mathrm{H}$-section columns. Journal of Constructional Steel Research. 2013;80:243-51.

[22]Espinos A, Romero ML, Lam D. Fire performance of innovative steel-concrete composite columns using high strength steels. Thin-Walled Structures. 2016;106:113-28.

[23]Zhang C, Wang GY, Xue SD, Yu HX. Experimental research on the behaviour of eccentrically loaded SRC columns subjected to the ISO-834 standard fire including a cooling phase. International Journal of Steel Structures. 2016;16:425-39.

[24] Han LH, Huo JS, Wang YC. Compressive and flexural behaviour of concrete filled steel tubes after exposure to standard fire. Journal of Constructional Steel Research. 2005; 61:882-901.

[25] Yang H, Han LH and Wang YC. Effects of heating and loading histories on post fire cooling behaviour of concrete filled steel tubular columns, Journal of Constructional Steel Research. 2008; 64(5):556-70.

[26]Huo J, Huang G and Xiao Y. Effects of sustained axial load and cooling phase on post-fire behaviour of concrete-filled steel tubular stub columns, Journal of Constructional Steel Research. 2009; 65:1664-1676.

[27] Kodur VKR, Raut NK, Mao XY and Khaliq W. Simplified approach for evaluating residual strength of fire-exposed reinforced concrete columns. Materials and Structures, 46:2059-2075, 2013. DOI 10.1617/s11527-013-0036-2

[28] Liu F, Gardner L and Yang H. Post-fire behaviour of reinforced concrete stub columns confined by circular steel tubes, Journal of Constructional Steel Research. 2014; 102:82-103.

[29]Liu F, Yang H and Gardner L. Post-fire behaviour of eccentrically loaded reinforced concrete columns confined by circular steel tubes, Journal of Constructional Steel Research. 2016;122, 
$495-510$.

[30]Li W, Luo Z, Tao Z, Duan WH and Shah SP, Mechanical behavior of recycled aggregate concrete-filled steel tube stub columns after exposure to elevated temperatures, Construction and Building Materials. 2017; 146: 571-581.

[31]Ibañez C, Bisby L, Rush D, Romero ML and Hospitaler A. Post-heating response of concrete-filled steel tubular columns under sustained loads, Structures. 2019. https://doi.org/10.1016/j.istruc.2019.04.003

[32]Rush DI, Bisby LA, Jowsey A, Lane B, Residual capacity of fire-exposed concrete-filled steel hollow section columns, Engineering Structures. 2015;100: 550-563.

[33] Imani R, Mosqueda G, Bruneau M. Finite Element Simulation of Concrete-Filled Double-Skin Tube Columns Subjected to Postearthquake Fires, Journal of Structural Engineering. 2015;141(12):04015055.

[34]Zhou K, Han L-H. Experimental performance of concrete-encased CFST columns subjected to full-range fire including heating and cooling, Engineering Structures. 2018;165:331-348.

[35]Zhou K, Han L-H. Modelling the behaviour of concrete-encased concrete-filled steel tube (CFST) columns subjected to full-range fire, Engineering Structures. 2019;183:265-280.

[36] Kirby BR, Lapwood DG and Thomson G. The Reinstatement of Fire Damaged Steel and Iron Framed Structures, 1986, British Steel Corporation (now Corus), London, UK.

[37] Concrete Society, Assessment and Repair of Fire-Damaged Concrete Structures. 1990. Technical Report No. 15, The Concrete Society, UK.

[38] Wang YC, Wald F, Vácha J, Hajpal M. Fire Damaged Structures. In Urban Habitat Constructions under Catastrophic Events, Leiden: CRC Press/Balkema, 2010, p. 293-302. ISBN 978-0-415-60686-8.

[39] Han LH, Tan QH, Song TY. Fire Performance of Steel Reinforced Concrete Columns. Journal of Structural Engineering. 2015;141:04014128.

[40]Han LH, Zhou K, Tan QH, Song TY. Performance of Steel-Reinforced Concrete Column after Exposure to Fire: FEA Model and Experiments. Journal of Structural Engineering. 
2016;142:04016055.

[41]Dassault Systèmes Simulia Corp. Abaqus analysis user's manual, 2010, Providence, RI, USA.

[42] Song TY, Han LH, Yu HX. Temperature Field Analysis of SRC-Column to SRC-Beam Joints Subjected to Simulated Fire Including Cooling Phase. Advances in Structural Engineering, 2011;14(3): 353-366. https://doi.org/10.1260/1369-4332.14.3.353

[43]Zehfuß J and Lyzwa J. Thermische Materialeigenschaften Von Beton In Der Abkühlphase, in Tagungsband of Braunschweiger Brandschutz-Tage 2017, September 13-14, 2017 Braunschweig, Germany. Zehfuß J, Eds. Braunschweig. (In German)

[44] International Organization for Standardization (ISO). Fire resistance tests-elements of building construction. ISO 834-1975, Switzerland, Geneva.

[45]British Standard Institution (BSI). BS EN 1994-1-1:2004. Eurocode 4 - Design of composite steel and concrete structures; Part 1-2: General rules-Structural fire design. UK, London; 2014

[46] JGJ 138-2001. Technical specification for steel reinforced concrete composite structures. China architecture and building press, 2002, Beijing, China. (in Chinese).

[47] International Organization for Standardization (ISO). Fire-resistance tests-Elements of Building construction-Part 1: General requirements. ISO 834-1:1999. Switzerland, Geneva

[48] Kodur VKR, Wang TC, and Cheng FP. Predicting the fire resistance behavior of high strength concrete columns. Cement \& Concrete Composites. 2004,26(2), 141-153.

[49]Han LH, Yang H, Cheng SL, Residual Strength of Concrete Filled RHS Stub Columns after Exposure to High Temperatures, Advances in Structural Engineering. 2002;5(2):123-134.

[50]CECS 252:2009. Standard for building structural assessment after fire. China planning press. 2009, Beijing, China. (in Chinese)

[51]Barnett CR. BFD curve: a new empirical model for fire compartment temperatures. Fire Safety Journal. 2002;37: 437-463. 


\section{Captions for Tables}

Table 1 Summary of the investigated parameters

Table 2 Classification of damage 


\section{$\underline{\text { Tables }}$}

Table 1 Summary of the investigated parameters

\begin{tabular}{ccccc}
\hline Type & Parameters & Symbols & Values & Units \\
\hline \multirow{4}{*}{ Geometric parameters } & Sectional perimeter & $C$ & $400, \underline{\mathbf{6 0 0}}, 800,1000$ & $\mathrm{~mm}$ \\
& Sectional aspect ratio & $\beta$ & $\underline{\mathbf{1 . 0}}, 1.5,2.0$ & - \\
& Slenderness ratio & $\lambda$ & $17.5, \underline{\mathbf{3 5 . 0}}, 52.5,70.0$ & - \\
& Steel ratio & $\alpha$ & $\underline{\mathbf{4 \%}}, 6 \%, 8 \%$ & - \\
& Reinforcement ratio & $\rho$ & $\underline{\mathbf{1 \%}}, 2 \%, 3 \%$ & - \\
\hline \multirow{2}{*}{ Parameters related to } & Duration of fire exposure & $t_{\mathrm{h}}$ & $0,15,30, \underline{\mathbf{4 5}}, 60,90$ & $\mathrm{~min}$ \\
& Load eccentricity & $e / r$ & $\underline{\mathbf{0}}, 0.3,0.6,0.9$ & - \\
actions & Load ratio & $n$ & $\underline{\mathbf{0 . 2}}, 0.4,0.6$ & - \\
\hline \multirow{3}{*}{ Physical parameters } & Yield strength of steel section & $f_{\mathrm{y}}$ & $235, \underline{\mathbf{3 4 5}}, 420$ & $\mathrm{MPa}$ \\
& Yield strength of rebars & $f_{\mathrm{yb}}$ & $235, \underline{\mathbf{3 3 5}}, 400$ & $\mathrm{MPa}$ \\
& Cube strength of concrete & $f_{\mathrm{cu}}$ & $40, \underline{\mathbf{6 0}}, 80$ & $\mathrm{MPa}$ \\
\hline
\end{tabular}


Table 2 Classification of damage

\begin{tabular}{ccc}
\hline Categories & Descriptions & Measures \\
\hline $\begin{array}{c}\text { 1-Superficial } \\
\text { damage }\end{array}$ & $\begin{array}{c}\text { Surface of concrete darkened by smoke, no } \\
\text { spalling, no crazing, no exposed } \\
\text { reinforcement, no cracks }\end{array}$ & $\begin{array}{c}\text { Superficial repair: clear up the darkened } \\
\text { surfaces, no structural repairing measure } \\
\text { needed }\end{array}$ \\
\hline $\begin{array}{c}\text { 2-Minor } \\
\text { damage }\end{array}$ & $\begin{array}{c}\text { Slight crazing, minor spalling, no } \\
\text { reinforcement exposed, no cracks }\end{array}$ & $\begin{array}{c}\text { General repair: restore the durability of } \\
\text { surface concrete }\end{array}$ \\
\hline $\begin{array}{c}\text { 3-Moderate } \\
\text { damage }\end{array}$ & $\begin{array}{c}\text { Localized or considerable concrete spalling, } \\
\text { moderate crazing, minor or major cracking, } \\
\text { reinforcement exposed }\end{array}$ & $\begin{array}{c}\text { Major repair: repair, rehabilitate or replace } \\
\text { damaged parts to restore the structural } \\
\text { performance }\end{array}$ \\
\hline $\begin{array}{c}\text { 4-Extensive } \\
\text { damage }\end{array}$ & $\begin{array}{c}\text { Severe concrete explosive spalling, severe } \\
\text { buckling of steel section and reinforcement }\end{array}$ & \begin{tabular}{c} 
Unrepairable: scrap \\
\hline
\end{tabular} \\
\hline
\end{tabular}




\section{Captions for Figures}

Fig. 1. The fire-exposed building and the view of a post-fire interior SRC column

Fig. 2. A cross-section of an SRC column

Fig. 3. Stress-strain relationships of materials at different phases

Fig. 4. Interaction curves of an SRC column after fire exposure

Fig. 5. Post-fire failure modes of SRC columns

Fig. 6. Internal load share versus time relationships

Fig. 7. Influence of parameters on reduction coefficient $\left(k_{\mathrm{r}}\right)$

Fig. 8. Effect of fire exposure on the strength of SRC columns

Fig. 9. Simplified computation diagram for post-fire reduction coefficient $\left(k_{\mathrm{r}}\right)$

Fig. 10. Flowchart of post-fire assessment and design for repair

Fig. 11. Details of a fire-exposed SRC column (units: mm)

Fig. 12. Temperature $(\theta)$ versus time $(t)$ curves in a fire compartment

Fig. 13. Meshes and boundary conditions of the SRC column in the FEA model

Fig. 14. Interaction curves of the SRC column

Fig. 15. Moment $(M)$ versus curvature $(\phi)$ curves of the SRC column 


\section{$\underline{\text { Figures }}$}

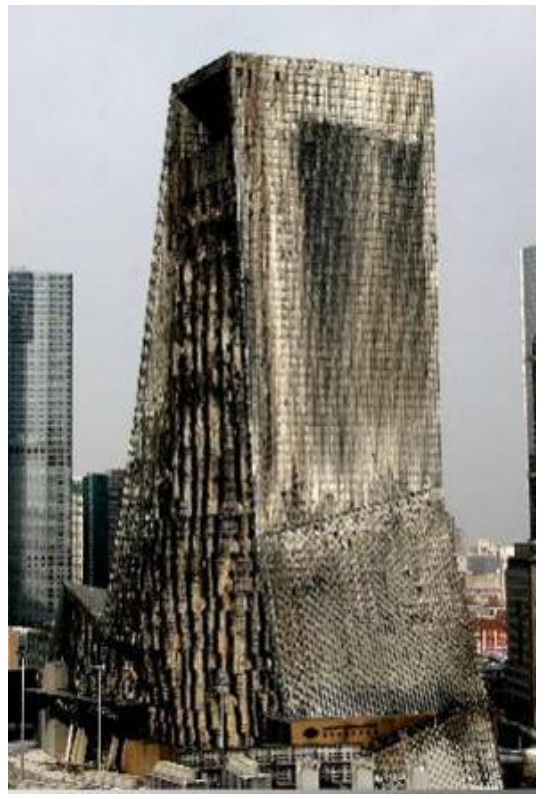

(a) The facade of the fire-exposed building

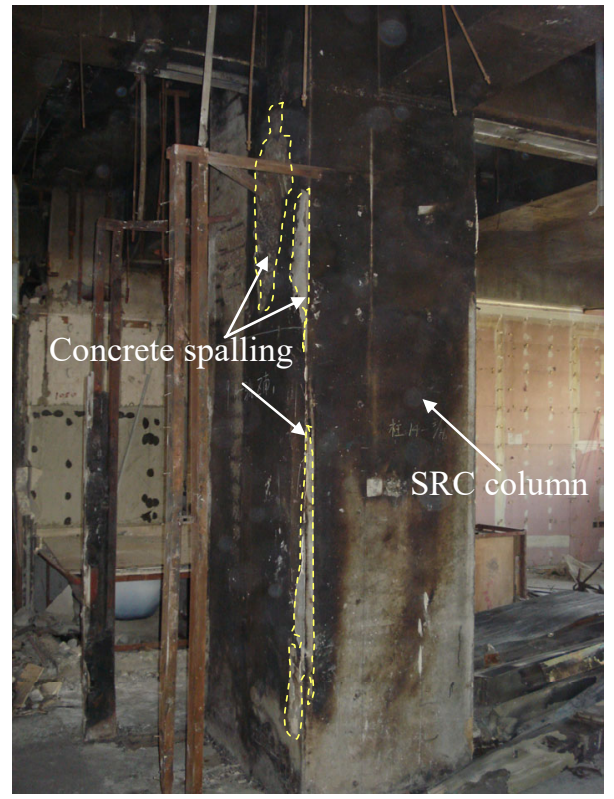

(b) A fire-exposed SRC column

Fig. 1. The fire-exposed building and the view of a post-fire interior SRC column 


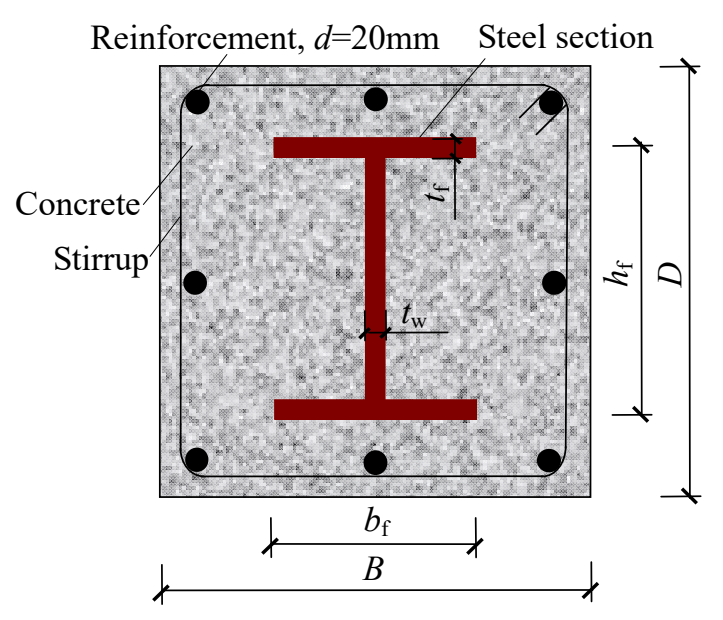

Fig. 2. A cross-section of an SRC column 


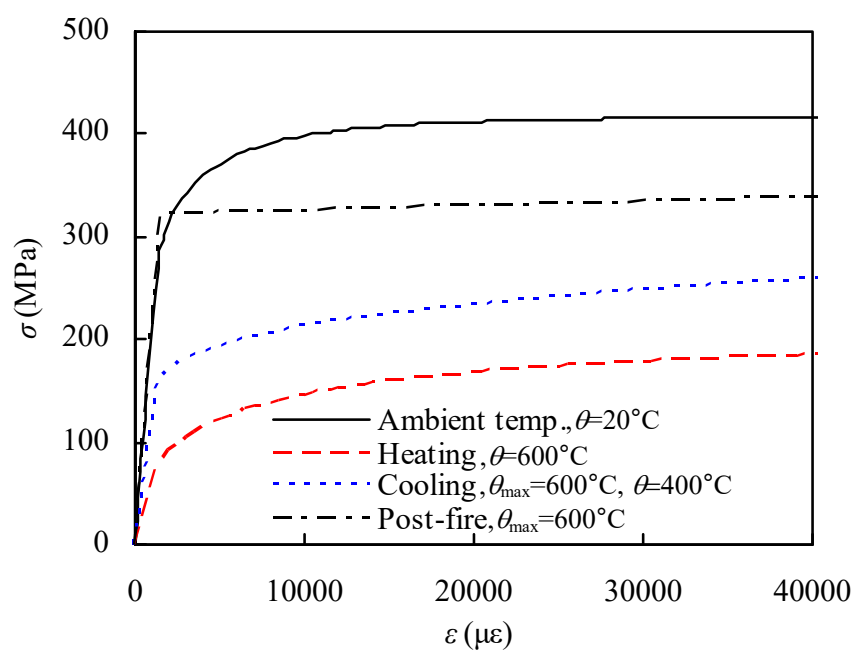

(a) Steel

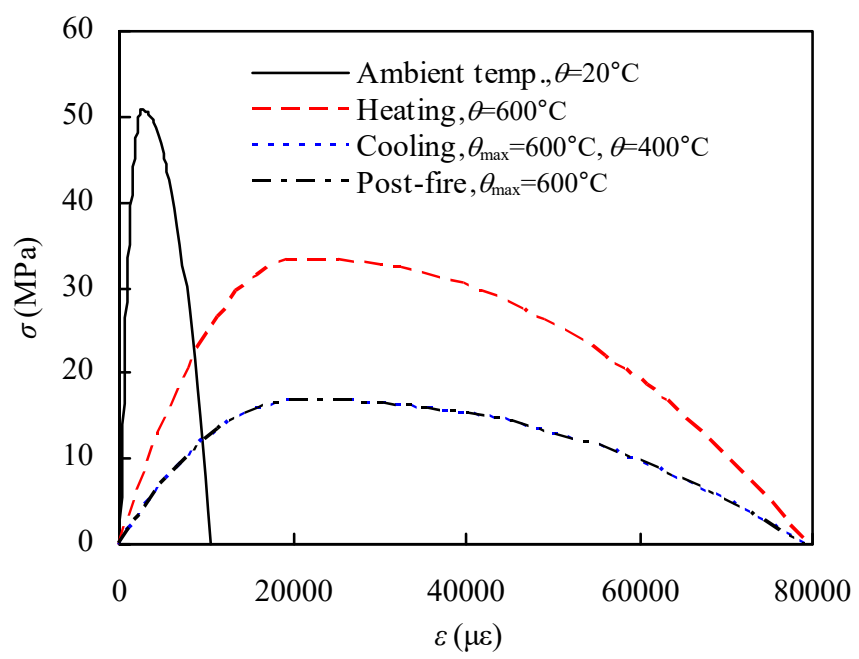

(b) Concrete

Fig. 3. Stress-strain relationships of materials at different phases 


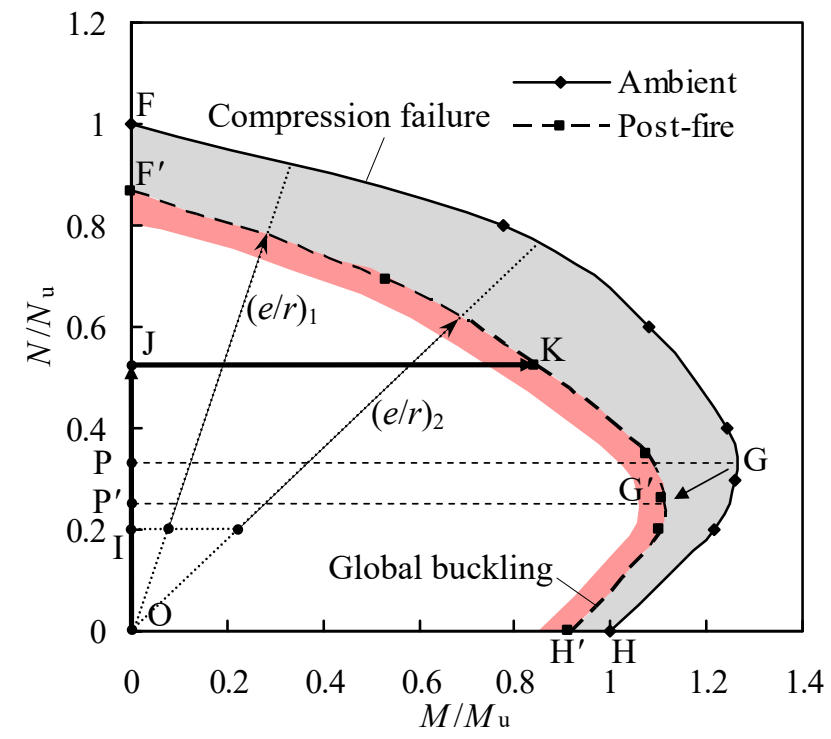

Fig. 4. Interaction curves of an SRC column after fire exposure 


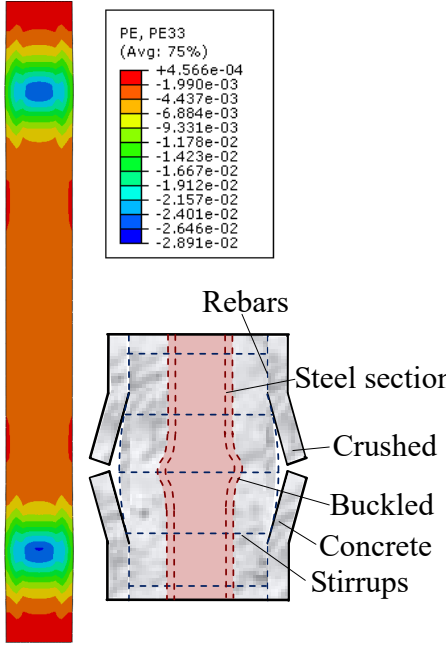

(a) Compression failure mode

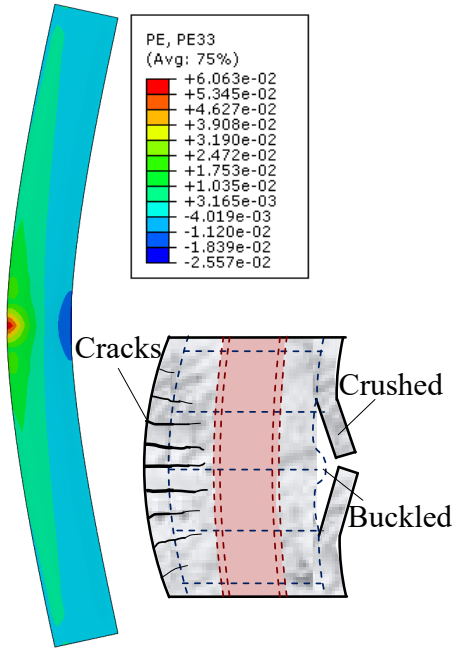

(b) Global buckling failure mode

Fig. 5. Post-fire failure modes of SRC columns 


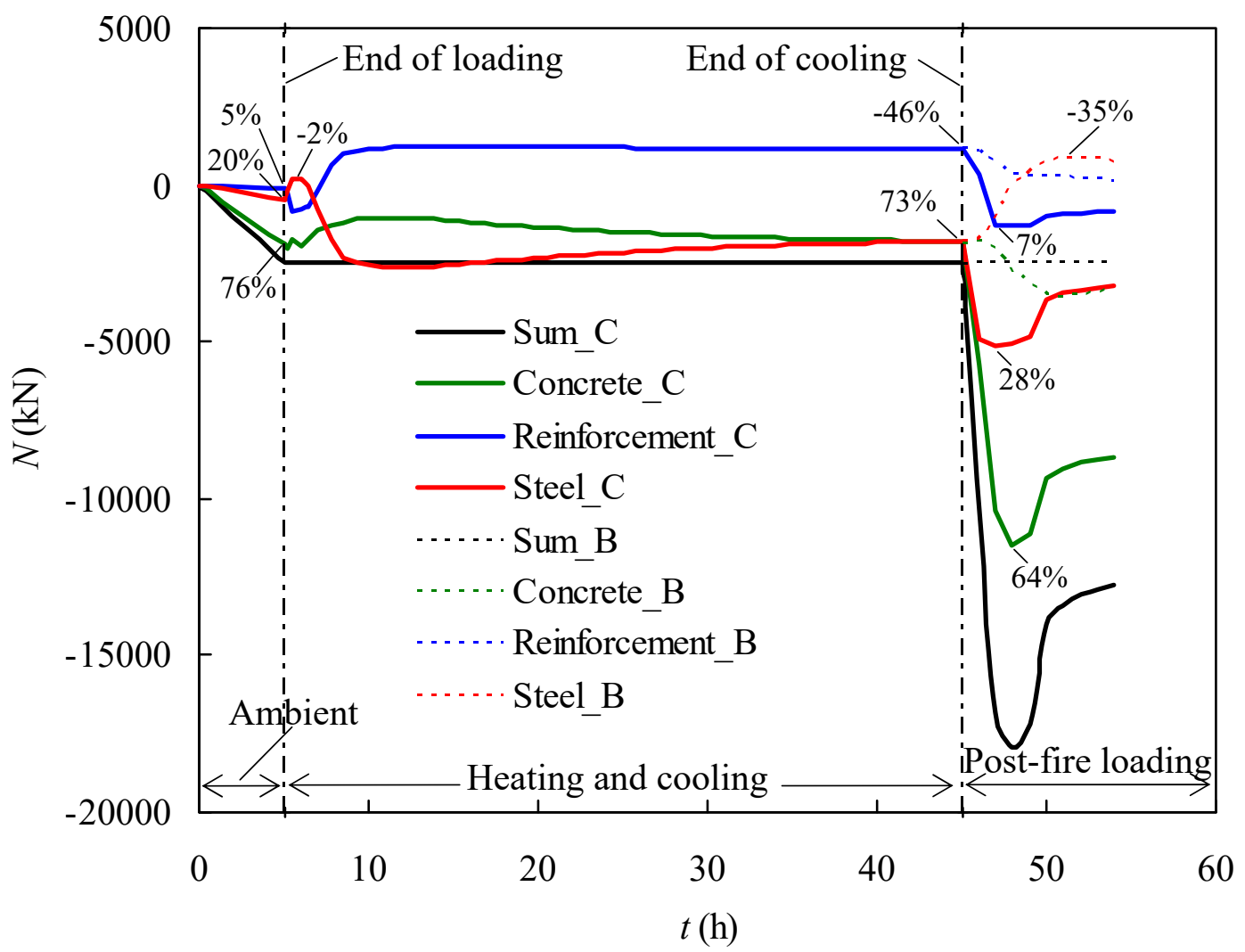

Fig. 6. Internal load share versus time relationships 


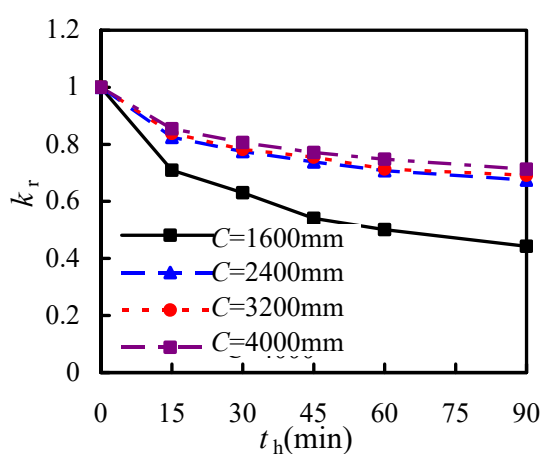

(a) Sectional perimeter $(C)$

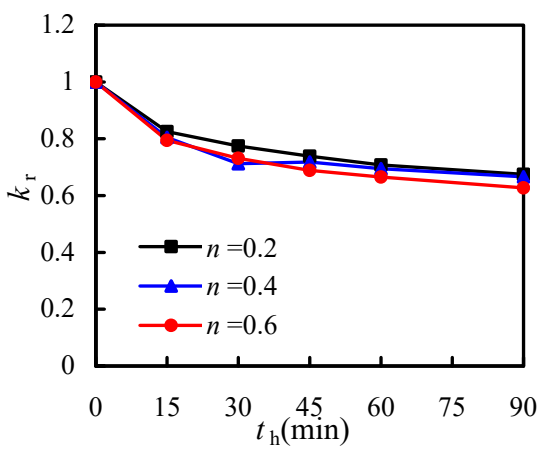

(d) Load ratio (n)

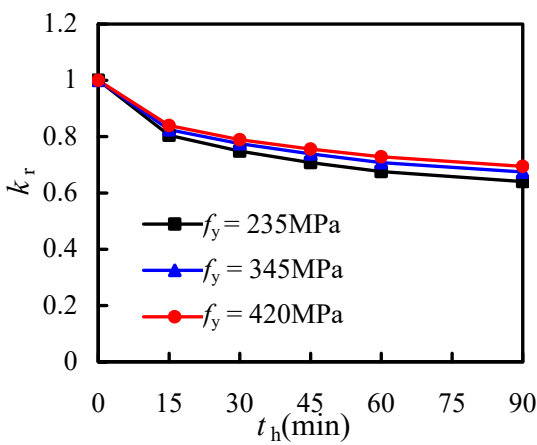

(g) Yield strength of steel section $\left(f_{\mathrm{y}}\right)$

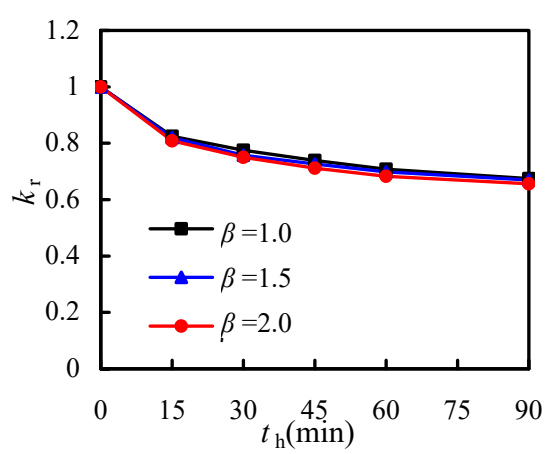

(b) Sectional aspect ratio $(\beta)$

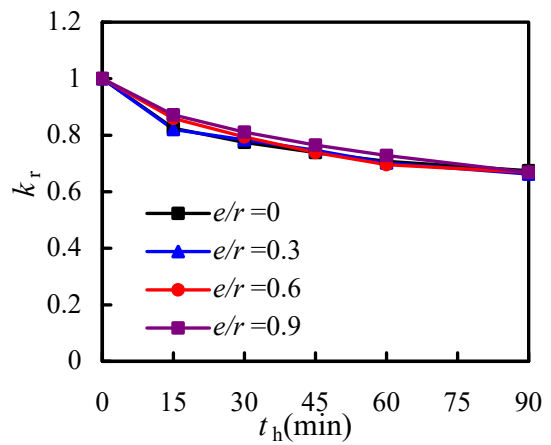

(e) Load eccentricity ratio $(e / r)$

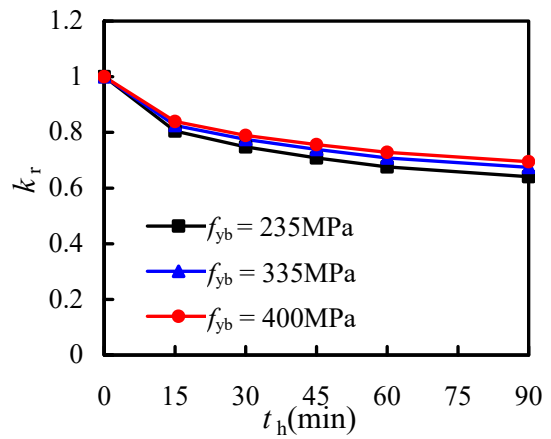

(h) Yield strength of longitudinal rebar $\left(f_{\mathrm{yb}}\right)$

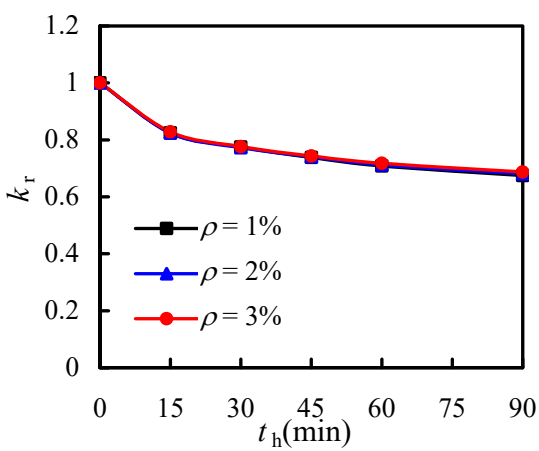

(j) Reinforcement ratio $(\rho)$

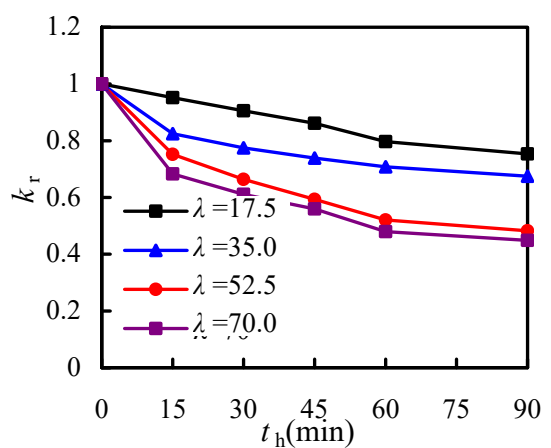

(c) Slenderness ratio $(\lambda)$

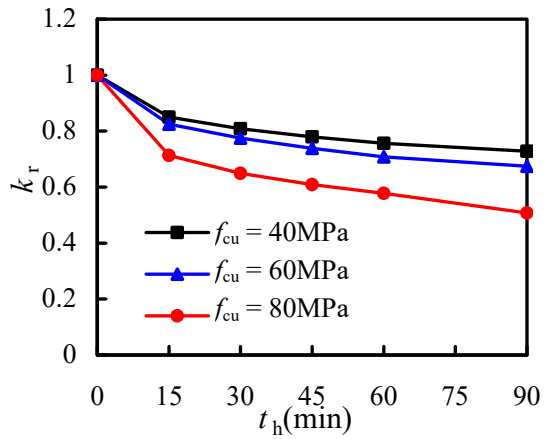

(f) Cube strength of concrete $\left(f_{\text {cu }}\right)$

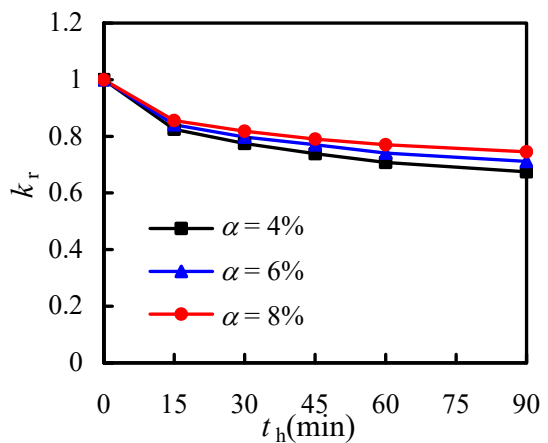

(i) Sectional steel ratio $(\alpha)$

Fig. 7. Influence of parameters on reduction coefficient $\left(k_{\mathrm{r}}\right)$ 


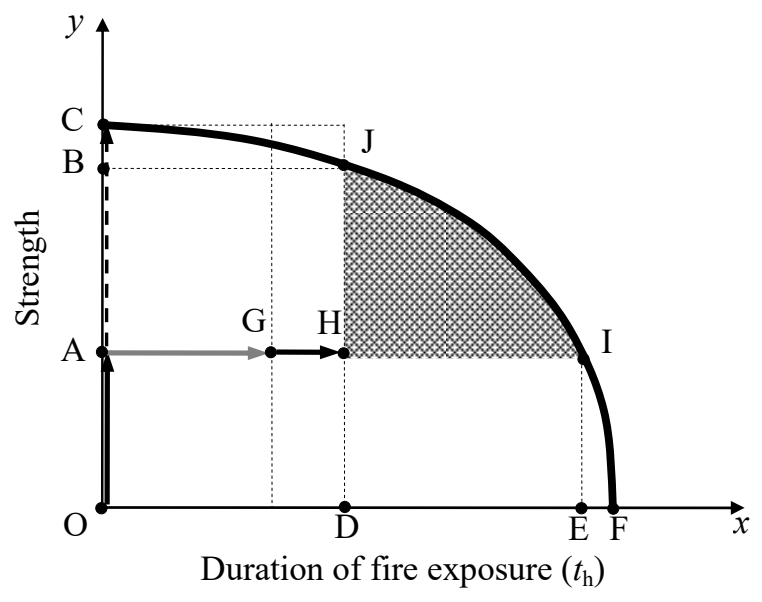

Fig. 8. Effect of fire exposure on the strength of SRC columns 


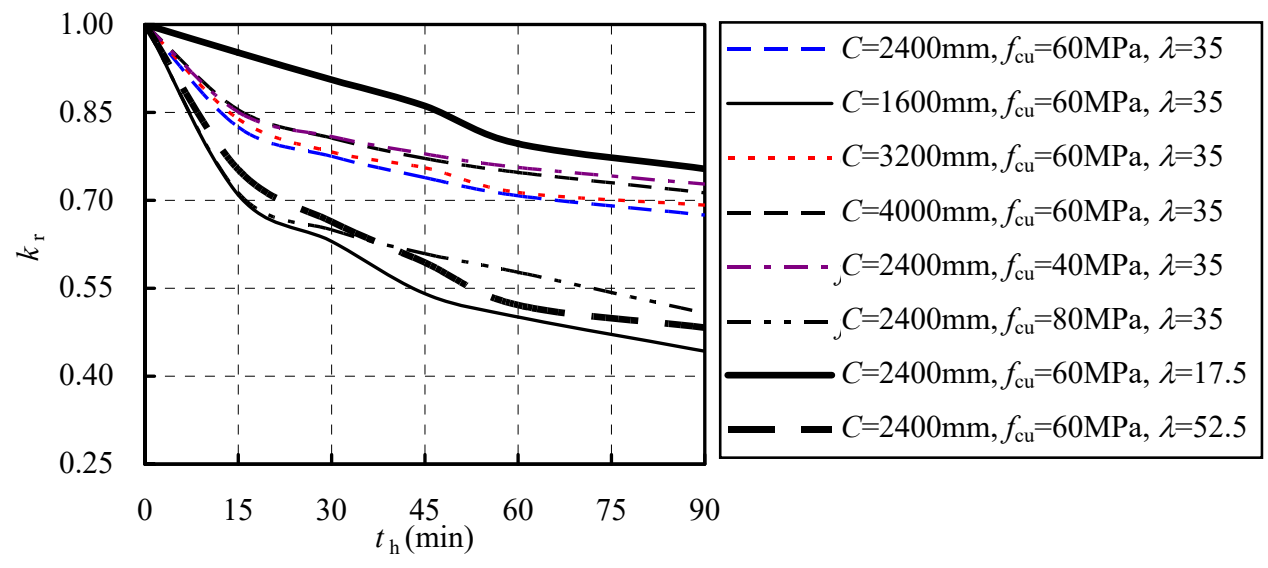

Fig. 9. Simplified computation diagram for post-fire reduction coefficient $\left(k_{\mathrm{r}}\right)$ 


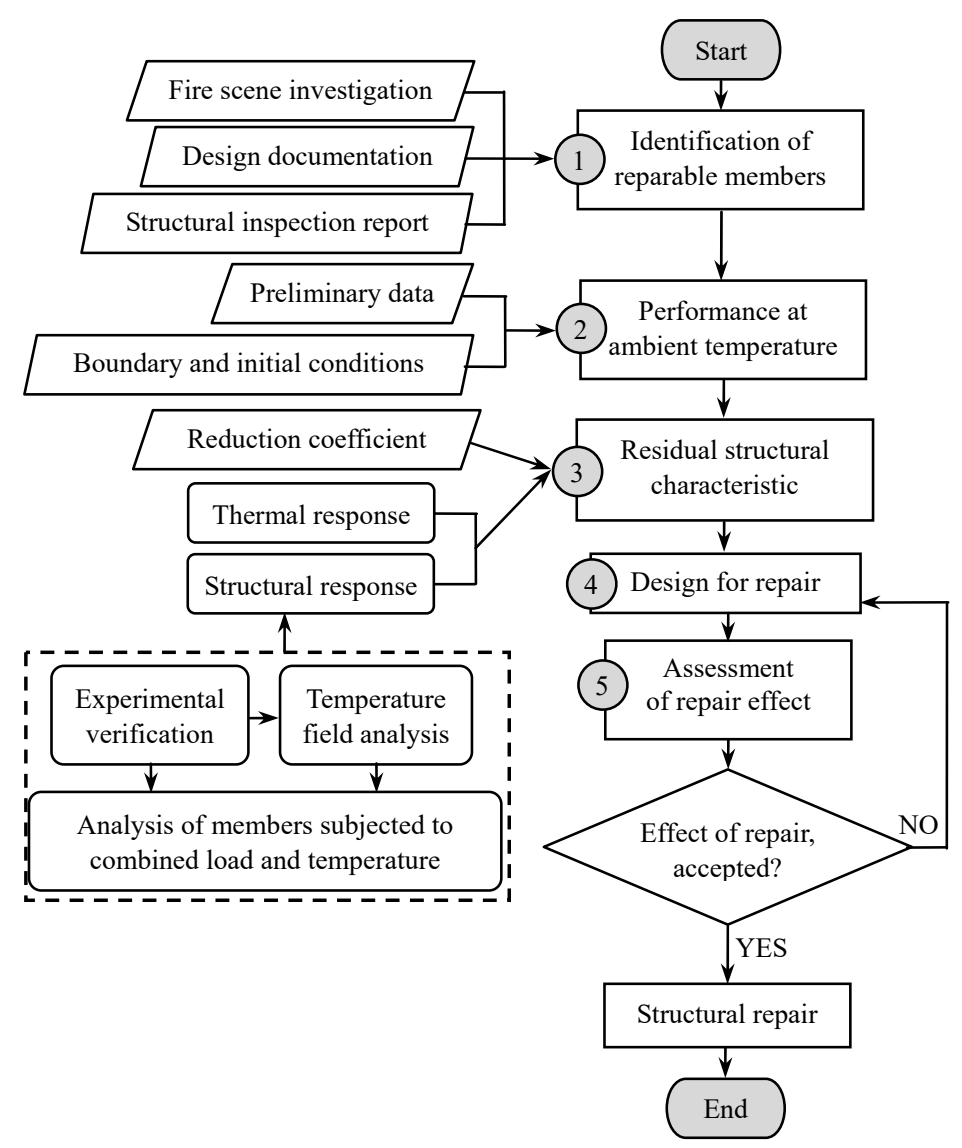

Fig. 10. Flowchart of post-fire assessment and design for repair 


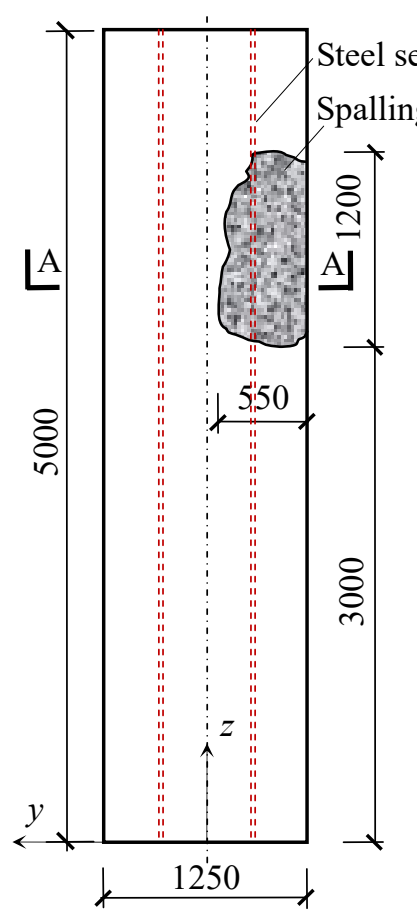

(a) Elevation

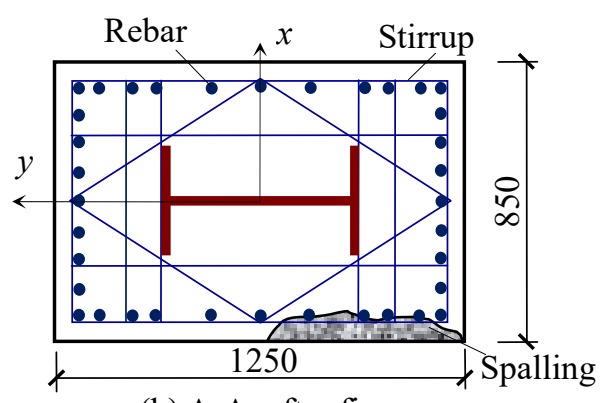

(b) A-A: after fire

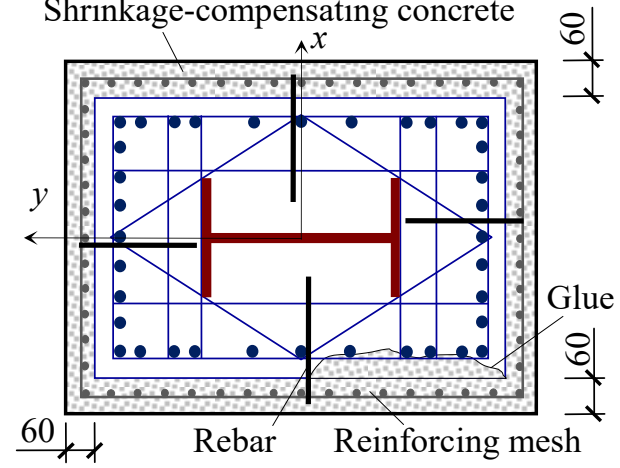

(c) A-A: after repair

Fig. 11. Details of a fire-exposed SRC column (units: $\mathrm{mm}$ ) 


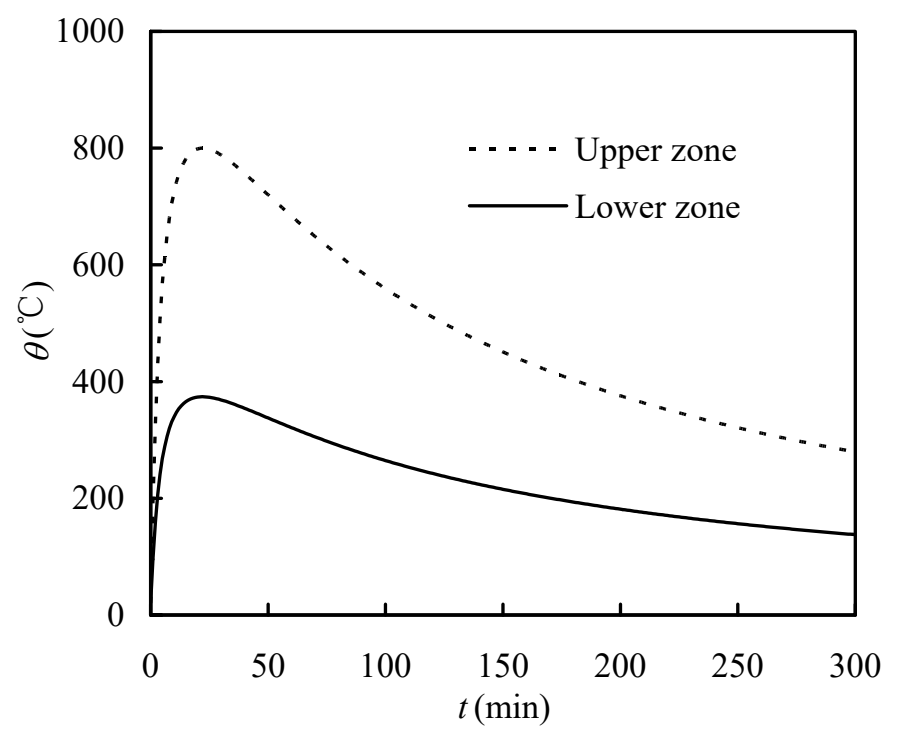

Fig. 12. Temperature $(\theta)$ versus time $(t)$ curves in a fire compartment 


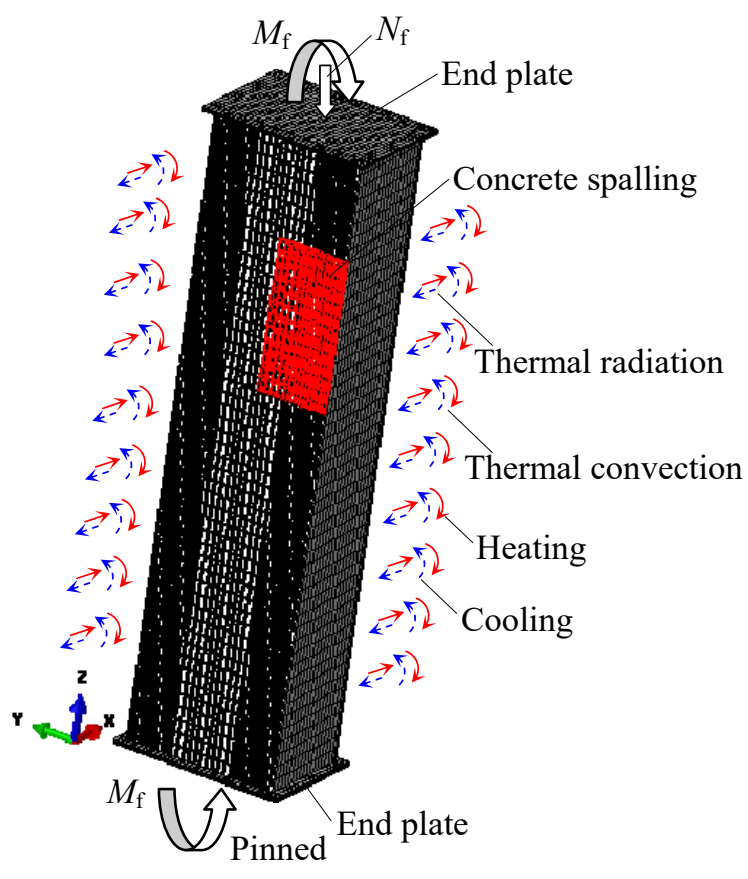

Fig. 13. Meshes and boundary conditions of the SRC column in the FEA model 


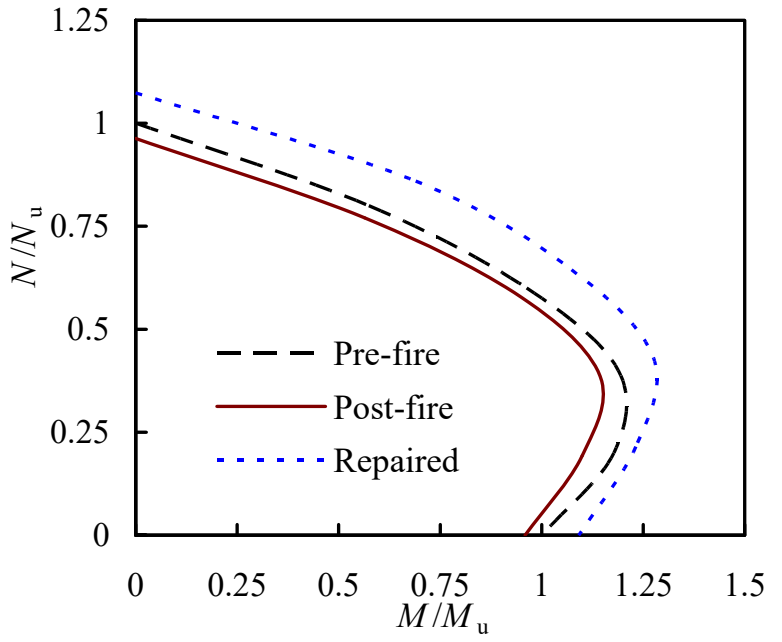

(a) About major axis $\mathrm{x}$

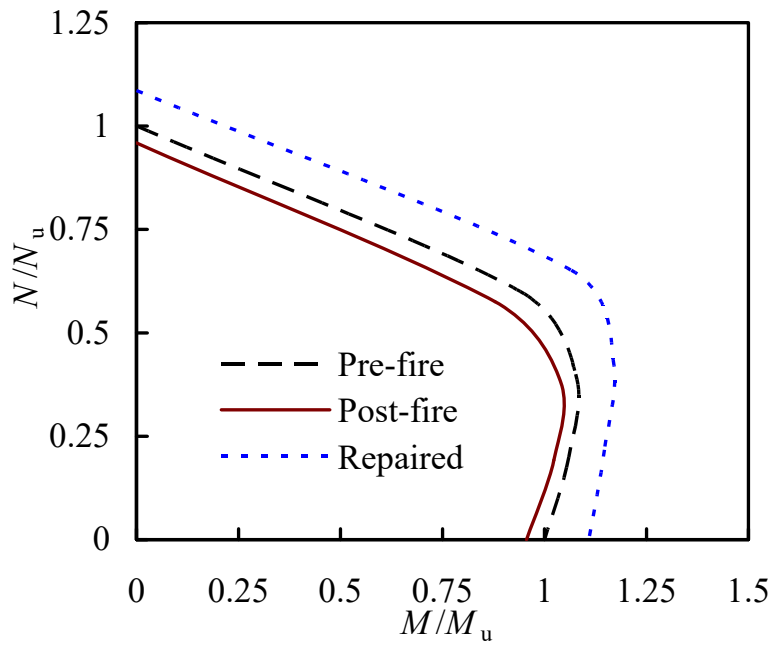

(b) About minor axis y

Fig. 14. Interaction curves of the SRC column 


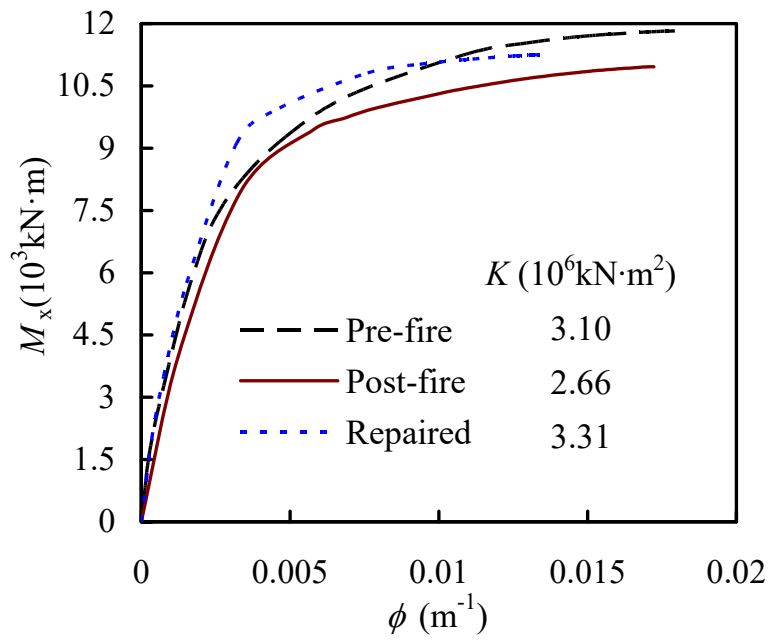

(a) About major axis $\mathrm{x}$

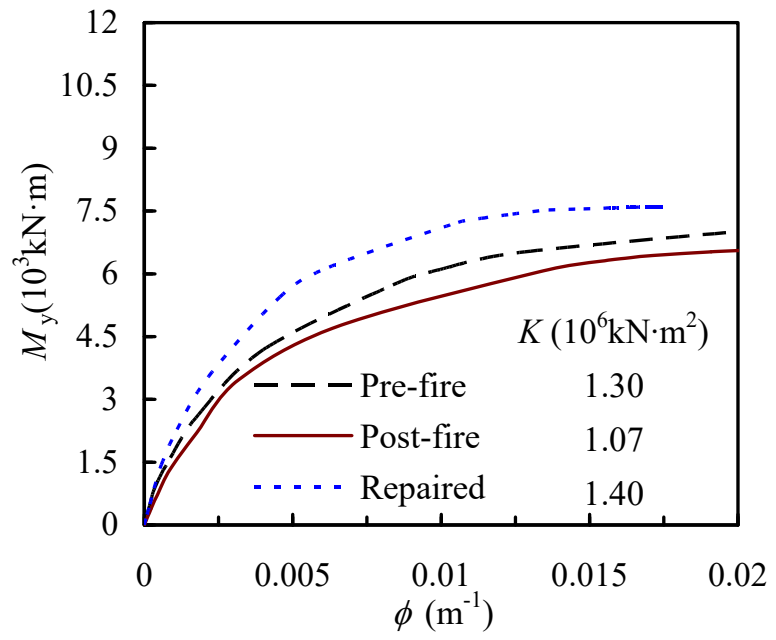

(b) About minor axis y

Fig. 15. Moment $(M)$ versus curvature $(\phi)$ curves of the SRC column 